\title{
Los envases y el servicio municipal de recogida y tratamiento de residuos
}

\author{
Joan Perdigó i Solà \\ Director del Servicio Jurídico de la Entidad Metropolitana de los \\ Servicios Hidráulicos y del Tratamiento de Residuos \\ Profesor asociado de la Universidad de Barcelona
}

Sumario: 1. EL SERVICIO MUNICIPAL DE GESTIÓN DE RESIDUOS Y LA TITULARIDAD SOBRE LOS MISMOS. 1.1. Modificaciones introducidas por la nueva Ley de Residuos de 1998. 1.2. Propiedad de los residuos municipales. 2. ANTECEDENTES DE LA NORMATIVA SOBRE ENVASES: ALEMANIA, BÉLGICA Y FRANCIA. 3. LA DIRECTIVA 94/62/CE. 4. LA TRANSPOSICIÓN ESPAÑOLA: LA LEY DE ENVASES Y RESIDUOS DE ENVASES DE 24 DE ABRIL DE 1997. 4.1. Objetivos generales. 4.2. Objetivos de prevención. 4.3. Objetivos de valorización y de reciclaje. 4.4. Sistemas de gestión de los envases usados y de los residuos de envases. 4.4.1. Sistema de depósito, devolución y retorno. 4.4.2. Los sistemas integrados de gestión de envases y residuos de envases. 4.4.3. Los sistemas integrados de gestión con participación de las entidades locales. 4.4.4. Financiación de la participación de las entidades locales en los sistemas integrados. 4.4.5. Naturaleza de la financiación de los sistemas integrados a los entes locales que participan en su gestión y su eventual sujeción al IVA. 4.4.6. Titularidad sobre los residuos en envases en los sistemas integrados con participación de la entidad local. 4.5. La intervención de las Comunidades Autónomas en la participación de las entidades locales en los sistemas integrados de gestión. 4.6. Planificación y programación. 5. ALGUNAS CONCLUSIONES.

\section{EL SERVICIO MUNICIPAL DE GESTIÓN DE RESIDUOS Y LA TITULARIDAD SOBRE LOS MISMOS}

\subsection{Modificaciones introducidas por la nueva Ley de Residuos de 1998}

La recogida y tratamiento de basuras, desechos o residuos en general es una típica competencia municipal encuadrada en los servicios que, en materia de salubridad e higiene públicas, ya desde la Instrucción de 23 de junio de 1813 , tanto la legislación local como la sanitaria vienen atribuyendo a los Municipios. En la Ley 7/1985, de 2 de abril, reguladora de las Bases del Régimen Local, la gestión de residuos se contempla en sus tres dimensiones: recogida, tratamiento y aprovechamiento. Con carácter general se trata de una de las materias sobre las que la legislación estatal y autonómica han de atribuir competencia a los municipios [art. 25.2 1)]; la recogida es un servicio mínimo obligatorio para toda clase de municipios y el tratamiento lo es para los de más de 5.000 
habitantes (art. 26); asimismo este servicio es declarado esencial y reservado a los entes locales (art. 86.3) '.

La legislación sectorial en la materia estaba formada hasta hace poco por la Ley 14/1986, de 25 de abril, General de Sanidad (art. 42.3), que contempla los residuos urbanos como una responsabilidad de las entidades locales y por la Ley 42/1975, de 19 de noviembre, modificada por el Real Decreto Legislativo $1163 / 1986$, de 13 de junio ${ }^{2}$. Esta última ha sido muy recientemente derogada y sustituida por la Ley 10/1998, de 21 de abril, de Residuos, cuyos arts. 4.3 y 20 , dedicados a los entes locales, son declarados básicos por la Disposición final $2{ }^{a}$ de la Ley. En estos preceptos se modifica el régimen de obligatoriedad del servicio establecido en el art. 26 de la Ley Básica de Régimen Local, en el doble sentido de que a la obligatoriedad general de la recogida, para toda clase de municipios, se añade la eliminación —en vertedero controlado- por lo menos; y por lo que respecta a las poblaciones de más de 5.000 habitantes, sus Ayuntamientos vienen obligados a implantar, a partir del 1 de enero del 2001 -Disposición transitoria $3 .^{\text {a }}$ - sistemas de recogida selectiva que permitan el reciclado y otras formas de valorización de los residuos. Esta última obligación, sin embargo, en la medida en que la recogida selectiva de envases se remite a su legislación específica, queda muy limitada, máxime si —a diferencia de la Ley catalana de Residuos de 1993 - no incluye expresamente la recogida segregada de residuos orgánicos.

En la Ley 10/1998 la expresión tradicional de «residuos sólidos urbanos» ha sido sustituida por la de «residuos urbanos o municipales». Este cambio obedece a la adaptación al ordenamiento comunitario europeo, que utiliza la expresión de «residuos municipales», adoptada en la Directiva 75/442/CEE, modificada por la Directiva 91/156/CEE, y a la que responde el Catálogo Europeo de Residuos, aprobado por la Decisión de la Comisión Europea 94/3/CE. A la lista de este Catálogo Europeo —epígrafe 2000 00: residuos municipales u residuos asimilables procedentes del comercio e instituciones incluyendo fracciones recogidas selectivamente- el art. 3 b) de la nueva Ley de Residuos añade los animles domésticos muertos, los muebles y enseres los vehículos abando-

1 P. MENÉNDEZ, «Una interpretación renovada de la reserva de servicios esenciales en favor de las entidades locales», REDA, $\mathrm{n}^{\circ} 89,1996$.

2 Sobre las competencias municipales en materia de residuos, así como sobre el correspondiente servicio público: R. Martín Mateo, Tratado de Derecho Ambiental, Vol. II, Trivium, Madrid, 1992, págs. 509 a 566 y Nuevo ordenamiento de la basura, Trivium, Madrid, 1998; M. J. MonToro, «Residuos Sólidos», en Derecho del Medio Ambiente y Administración Local, Civitas, Madrid, 1996; A. PEÑALVER, La regulació municipal dels residus, Cedecs, Barcelona, 1997; F. LLISET, «Residuos sólidos urbanos», en Derecho Local Especial II, Madrid, 1997; J. PERDIGO, «Marco legal» en Programa Metropolitano de Gestión de Residuos Municipales de Barcelona, aprobado el 17 de julio de 1997, Barcelona, 1998, http://www.ema-amb.com/ 
LOS ENVASES Y EL SERVICIO MUNICIPAL DE RECOGDA ...

nados, y los escombros procedentes de obras menores de construcción y reparación domiciliarias ${ }^{3}$.

\subsection{Propiedad de los residuos municipales}

Tradicionalmente se han calificado los residuos urbanos o municipales, como bienes patrimoniales o privativos del Municipio. La propiedad del Ayuntamiento sobre los residuos municipales se establecía en el art. 3.2 de la Ley de Residuos Sólidos Urbanos, desde el momento de la entrega. En los mismos términos, el art. 20.1 de la Ley de Residuos contempla la adquisición de dicha propiedad, añadiendo que los poseedores de los residuos quedan exentos de la responsabilidad por daños siempre que la entrega se haya producido de conformidad con las ordenanzas locales y demás normas de aplicación.

Aunque no existe una declaración legal explícita sobre la naturaleza, demanial o patrimonial, de esta propiedad municipal sobre los residuos, la inclinación por la segunda es consecuencia de la relación y concordancia entre los preceptos el art. 610 del Código Civil, el régimen de los mismo, regulado por el art. 20.1 de la Ley de Residuos, caracterizado por el desprendimiento del poseedor, y el segundo párrafo del art. 344 del Código Civil, que declara bienes patrimoniales del Municipio todos aquellos que no son de dominio público. Es también en base al Código Civil francés que Michel PrIEUR ${ }^{4}$ vincula naturaleza de los residuos a la noción de res derelicta del Derecho romano. El régimen patrimonial de los residuos municipales es pues el de los bienes privativos de los entes locales, regulado en el art. 80.2 de la Ley Básica de Régimen Local y en el Reglamento de Bienes de las Entidades Locales, aprobado por el Real Decreto 1372/1986, de 13 de junio.

Esta calificación de los residuos municipales como bienes patrimoniales no ofrecía problemas mientras el acento del servicio de gestión de residuos se ponía en la recogida y la disposición final en vertedero. En la actualidad, cuando parece claro que hay que superar la recogida indiscriminada y avanzar hacia la recogida segregada de la fracción orgánica y hacia las recogidas selectivas de las diversas fracciones inorgánicas, y cuando el protagonismo lo adquiere el aprovechamiento, reciclaje o valorización de los residuos, la calificación de éstos como bienes privativos empieza a ser más problemática.

3 La Ley catalana 6/1993 de Residuos adoptó la denominación comunitaria estricta de «residuos municipales»; por el contrario la muy reciente Ley gallega 10/1997 mantiene, como título, el de Ley de Residuos Sólidos Urbanos.

4 M. Prieur, Droit de l'Environnement, Dalloz, 3. e edición, París, 1996, págs. 565 y 566. 
Por de pronto y precisamente en base a la naturaleza patrimonial de los residuos municipales, el Tribunal Superior de Justicia de Castilla y León tiene establecida una chocante línea jurisprudencial que ataca directamente la financiación del tratamiento y la disposición final de los residuos municipales. Primero en Sentencia de 20 de diciembre de 1993 y después, por lo menos, en otra de 31 de enero de 1997, la Sala de lo Contencioso-Administrativo de Valladolid entiende que la obligación de poner los residuos sólidos urbanos a disposición del Ayuntamiento se ampara en la potestad de establecer tasas sobre el servicio de recogida, en la medida que los beneficiarios son los vecinos. Pero, a partir de la recogida «..., la posterior eliminación favorece sólo a los Ayuntamientos propietarios de los mismos,...», de forma que la recepción y solicitud obligatorias alcanzan a la entrega de los residuos pero no a la eliminación. De todo ello deduce el referido Tribunal Superior que queda «descartada su financiación por el sistema de tasas, que presupone, por definición, la existencia de un particular directamente beneficiado por la actividad administrativa» ${ }^{5} \mathrm{Si}$ esta afirmación se hace acerca de la disposición final en vertedero, imaginemos lo que diría la Sala en cuestión en un supuesto de tratamiento con valorización de la que resulten algún tipo de ingresos patrimoniales para la Administración municipal.

Que sepamos estas Sentencias del Tribunal Superior de Justicia de Castilla y León no han sido confirmadas por el Tribunal Supremo. En todo caso es obvio que en las mismas se omiten varias cuestiones fundamentales, que deberían ser atendidas, en su caso, por el Alto Tribunal:

a) En municipios de más de 5.000 habitantes, el tratamiento de los residuos es un servicio tan obligatorio como el de recogida. Y en los de menor población también, sin perjuicio de que la obligatoriedad ya no se puede predicar del Ayuntamiento sino, con carácter general, de la Diputación Provincial o de la Comunidad Autónoma.

b) De conformidad con las Directivas 75/442 y $91 / 156 / \mathrm{CEE}$, incluso con la sola transposición de la primera por el Real Decreto Legislativo 1163/1986, la recogida, el tratamiento y la valorización de los residuos, junto con la disposición final de las fracciones no valorizables, son actividades inseparables, tanto técnica como jurídicamente. Por tanto, el beneficio a los particulares, que constituye el hecho imponible de la tasa, se produce con la prestación, por parte de la entidad o entidades locales correspondientes, del ciclo completo de operaciones que integran la gestión de los residuos municipales.

5 Más increíble que las propias sentencias es que la primera de ellas resulta de un recurso interpuesto por la Administración General del Estado ( $i$ ?) contra una Ordenanza fiscal del Ayuntamiento de León. 
c) El art. 86.3 de la Ley Básica de Régimen Local declara servicios esenciales tanto la recogida, como el tratamiento y el aprovechamiento de los residuos, de lo que se deduce que el tratamiento, la valorización y la disposición final no son unas actividades internas o «domésticas» de la entidad local, sino que forman parte de un mismo servicio público que — con el carácter de esencial- se presta en beneficio de los contribuyentes, en todas sus fases. El art. 166.1 de la Ley de Régimen Local de 1955 hacía algo equivalente cuando declaraba la recogida y - ya entonces - el aprovechamiento de basuras como servicio municipalizable con monopolio.

Afirmar, pues, que la eliminación de los residuos no puede ser objeto de una tasa o de cualquier otra clase de contraprestación de carácter público, es una barbaridad tan grande como afirmar que la captación y la potabilización del agua o el saneamiento de las aguas residuales no pueden ser objeto de tasa, precio o tarifa alguno, porque el servicio obligatorio se reduce al suministro domiciliario y al alcantarillado.

De todas formas, estas sentencias ponen de manifiesto que la calificación de los residuos municipales como bienes patrimoniales puede aparentar que toda la actividad posterior a la recogida —operación que precisamente consagra la propiedad municipal - es equiparable a la simple gestión de bienes patrimoniales, sujeta a las reglas del Derecho privado y no del Derecho administrativo, de lo que también se deduciría que las operaciones de tratamiento, valorización y disposición no son un servicio público, sino una mera administración del patrimonio. Pero es perfectamente posible afirmar —porque así lo establece la leyque el hecho de que un servicio tenga por objeto unos bienes de carácter patrimonial no contradice su carácter de público Ya sucedía así cuando, en aplicación del art. 13 de la Ley de Aguas de 1879 las aguas residuales también se calificaban de bien patrimonial del municipio y, sin embargo, el alcantarillado, la depuración y el aprovechamiento de dichas aguas residuales eran declarados servicios públicos de competencia municipal por el art. 101 c) de la Ley de Régimen Local de 1955.

Pero aunque, desde el punto de vista del servicio público legalmente configurado, la realidad no se corresponde con la referida y supuesta apariencia, la duda generada por la clasificación patrimonial de los residuos persiste. El problema está en que los conceptos de bienes de dominio público y de bienes patrimoniales, aun distinguiéndose por su distinto fin y afectación, están excesivamente fundados en la «apropiación» o propiedad sobre la «cosa» en sentido jurídico-privado, y ello tanto en los patrimoniales como en los demaniales. De esta concepción privatista se deriva que, una vez la cosa ha pasado a ser res derelicta por su abandono, con la recogida municipal vuelve a tener un propietario, el Ayuntamiento; pero como el residuo no se ajusta a ninguna de 
las categorías de los bienes demaniales —naturales, de uso público o de servicio público- son calificados de patrimoniales, por exclusión.

Ahora bien, tal y como ha propugnado Luciano PAREJO ${ }^{6}$, la «cosa pública» debe considerarse desligada de las «cosas» o representaciones materiales, y ser concebida mejor como «una realidad jurídica distinta, cuyo núcleo jurídico radica en la relación de su titular - la entidad local, en nuestro caso- con el ordenamiento jurídico». En una línea parecida, el Tribunal Constitucional, en Sentencia 227/1988, de 29 de noviembre, sobre la Ley de Aguas de 1985, estableció luego (f.j. 14) que:

«..., la incorporación de un bien al dominio público supone una forma de apropiación por parte de los poderes públicos, sino una técnica dirigida primordialmente a excluir el bien afectado del tráfico jurídico, protegiéndolo de esta exclusión mediante una srie de reglas exhorbitantes de las que son comunes en dicho tráfico "iure privato". El bien de dominio público es asi ante todo "res extra commercium», que tiene esa eficacia esencial, puede perseguir distintos fines: tipicamente, ..., garantizar la gestión y utilización o equilibrada de un recurso esencial u otros similares. Dentro de esa amplia categoría de los bienes demaniales es preciso distinguir entre los singularmente afectados a un servicio público ... y aquellos otros que, en cuanto géneros, se declaran no susceptibles de apropiación privada en atención a sus características naturales unitarias.»

Y con respecto a esta segunda clase de bienes demaniales la Sentencia sigue diciendo:

«..., en la inclusión genérica de categorías enteras de bienes en el demanio, ..., subyacen prioritariamente otros fines constitucionalmente legitimos, vinculados en última instancia a la satisfacción de necesidades colectivas primarias, como por ejemplo, la que garantiza el art. 45 de la Constitución, o bien la defensa y la utilización racional de la riqueza del país, en cuanto subordinada al interés general (art. 128.I de la Constitución.»

En base a estos razonamientos, sería perfectamente pacífico atribuir a los residuos la condición de bienes de dominio público, en la medida que se trata de materiales cuya valorización no sólo permite renovar recursos sino que, además, contribuye a una utilización más racional y sostenible de los recursos naturales primarios. Si más que una forma de propiedad sobre la cosa, el dominio público implica un régimen jurídico de un determinado tipo de bienes ordenado a un fin legalmente establecido, nada sustantivo se opone a que los residuos en general, y en particular los municipales, sean considerados como demaniales. $\mathrm{Y}$, precisamente, esta prevalencia del régimen y del fin público se pone

6 L. Parejo Alfonso, «Dominio público: un ensayo de reconstrucción de su teoría general», RAP, n. $^{\text {os }} 100-102$, Vol. III, 1983, págs. 2.400 a 2.422. 
claramente de manifiesto en el art. 20.1 de la Ley de Residuos, cuando dispone que la entrega de los residuos urbanos al servicio municipal de recogida es una «obligación» de sus poseedores, que tiene por objeto «su reciclado, valorización o eliminación». Siempre en el bien entendido, claro está de que la naturaleza de los residuos municipales como dominio público lo sería en su calidad de «recurso», no como «cosas», de la misma forma que ocurre con las aguas continentales o con los hidrocarburos. Las alusiones a los recursos naturales, efectuadas tanto por el art. 132 como por el 45 y el 128 de nuestra Constitución, proporcionan sobrada base constitucional para la declaración de dominio público en el sentido indicado. Con respecto a los diferentes títulos de intervención pública y de delimitación de los derechos de propiedad y de empresa que se contienen en el art. 128 de la Constitución, no se trata tanto de acudir a la reserva al sector público de los residuos, al amparo del art. 128.2, como de hacer un uso instrumental de la demanialización del $132.1^{7}$. Y ello con el fin de hacer efectivos el principio general del art. 128.1, en el sentido de que «toda la riqueza del país está subordinada al interés general», independientemente de su titularidad ${ }^{8}$, y el deber de los poderes públicos de velar por «la utilización racional de todos los recursos, con el fin de proteger la calidad de vida y defender y restaurar el medio ambiente». Traducido todo ello en términos más actuales, plasmados en el art. 2 del Tratado de la Comunidad Europea estaríamos ante el deber, tanto de los poderes públicos como de los agentes económicos, de «promover un desarrollo armonioso y equilibrado de las actividades económicas, y un crecimiento sostenible y no inflacionista que respete el medio ambiente».

Es precisamente de todos estos preceptos constitucionales -estatales y comunitarios - de los que se desprende que la titularidad de las entidades locales sobre los residuos municipales no derivaría precisamente de su mera condición de res derelicta, generada por el abandono en la vía pública, sino de un determinado régimen jurídico ordenado a los deberes que, desde las más elevadas instancias normativas, se imponen a los poderes públicos. Es este ordenamiento ambiental el que atribuye a los poderes públicos locales el deber promover la valorización de los residuos como materiales y, en definitiva, como energía ${ }^{9}$.

\footnotetext{
7 Sobre las diferencias entre la demanialización del art. 132.1 de la Constitución y la reserva de recursos al sector público, ver de J. BARCELONA LLOP, La utilización del dominio público por la Administración: las reservas demaniales, Pamplona, 1996, pág. 147.

8 Y hay que tener en cuenta que la propiedad o la riqueza en acción, que sería el derecho de empresa amparado por el art. 38 de la Constitución, también se somete, en ese mismo precepto, a «las exigencias de la economía general y, en su caso, de la planificación».

9 La prevención y la reutilización, aunque anteriores a la valorización en el orden de prelación, son competencia del Estado y de las Comunidades Autónomas, y no de la Administración local, por su directa relación con la política económica e industrial.
} 
El hecho de que ordinariamente la afectación de bienes al servicio público tenga una función activa e instrumental, no impide que la afectación pueda ser tàmbién pasiva o a título de «objeto» del servicio. Esta misma vinculación pasiva se da entre el agua y el servicio público de abastecimiento a poblaciones ${ }^{10}$. Y así como la naturaleza demanial del agua, como recurso, no impide la apropiación, transformación y comercialización empresarial y privada de la cosa —en forma por ejemplo de refresco— la declaración de los residuos municipales como bienes de dominio público, tampoco sería óbice para su valorización y posterior comercialización. En esa fase final del proceso, los residuos adquirirían de nuevo el carácter de bienes patrimoniales, susceptibles de ser alienados mediante precio, lo que daría lugar a unos ingresos, lógicamente también, de carácter patrimonial para la entidad local titular del servicio de gestión de residuos.

Esta caracterización de los residuos municipales como bienes públicos, además de tener una funcionalidad general en el sistema de gestión, nos será útil también para determinar qué ocurre, desde el punto de vista patrimonial, con los residuos de envases cuando empiece a aplicarse la Ley 11/1997, y la responsabilidad sobre su recogida, tratamiento y valorización se desplaza de los municipios a los agentes económicos privados (envasadores y comerciantes).

\section{ANTECEDENTES DE LA NORMATIVA SOBRE ENVASES}

Durante los años setenta la residuos municipales experimentaron un incremento progresivamente creciente, tanto en peso como en volumen. Este incremento se ha debido a diferentes razones pero, sobre todo, a la sustitución de los productos a granel por los envasados y de los envases retornables y reutilizables por los no retornables, y a los nuevos tipos y materiales de los envases. Este protagonismo del envase en el ámbito de los residuos municipales es a su vez producto de una mezcla de razones: higiénico-sanitarias y de información al consumidor, pero también de nuevas políticas de logística y comercialización, por ejemplo las inducidas por la venta en grandes superficies. En el área metropolitana de Barcelona y durante 1996, por ejemplo, los residuos de envases constituyeron el $60 \%$ en volumen y el $30 \%$ en peso del total de residuos producidos en dicha conurbación ${ }^{11}$ durante ese año.

10 Aunque en el caso del agua, precisamente, la cuasi inconexa regulación del recurso natural y de su naturaleza demanial en la Ley de Aguas, y del servicio público de abastecimiento en la legislación de Régimen Local y en la legislación autonómica sectorial, plantean otros problemas más para el servicio que no para el recurso hídrico como bien de dominio público.

11 En el Programa Metropolitano de Gestión de Residuos Municipales, antes citado, el total de residuos producidos en 1996 se cifra en 1.290 .417 toneladas. 
En este espectacular incremento de los residuos generados por los envases, ni el sector privado ni los Estados tuvieron en cuenta que las colectividades locales tenían que hacerse cargo de las correspondientes externalidades negativas, o coste social, con el consiguiente aumento del gasto en inversiones y explotación de los servicios de gestión de residuos, y de su traslado al contribuyente, en forma de incremento de las tasas o de endeudamiento. En realidad, el servicio municipal tradicional, encuadrado en la higiene pública, tenía por objeto la recogida de los desechos orgánicos; la incorporación de los envases a los residuos municipales comporta pues un cambio cualitativo del servicio municipal que no se tiene en absoluto en cuenta.

El primer país comunitario en reaccionar ante ese fenómeno fue Dinamarca, con los Decretos 397/1981, de 2 de julio, y 95/1984, sobre consigna, depósito y reutilización de envases de cerveza y otras bebidas refrescantes y la prohibición de su comercialización en envases de lata. El Tribunal de Justicia de la Comunidad, en Sentencia de 20 de septiembre de 1988 y en resolución de impugnación de la Comisión Europea, confirmó en buena parte las disposiciones danesas, entendiendo que no infringían el ordenamiento comunitario sobre libre mercado. Teniendo en cuenta dicha sentencia, la República Federal Alemana siguió los pasos de Dinamarca y aprobó el Reglamento de 20 de diciembre de 1989, sobre depósito de envases de plástico para bebidas.

Antes de impugnar los decretos de Dinamarca, la Comisión promovió la aprobación por el Consejo Europeo de la Directiva 85/339/CEE, sobre envases de líquidos alimentarios, que no entró en vigor hasta el 3 de julio de 1987. Esta Directiva fue objeto de transposición en España mediante el Real Decreto $319 / 1991$, de 8 de marzo, que como en el resto de Estados miembros de la Comunidad, tuvo unos escasos resultados.

La insuficiencia, tanto a nivel estatal como comunitario, de regular solamente los envases de líquidos alimentarios llevó, primero a la República Federal Alemana y después a la Comisión Europea, a ordenar con carácter general, los envases y los residuos de envases. El fin perseguido es doble: fijar unos objetivos de valorización y, en particular, de reciclaje, y establecer mecanismos económicos de internalización, en los costes de producción, de las externalidades negativas provocadas por los residuos de envases ${ }^{12}$. Con respecto al segundo objetivo se trata de aplicar a los residuos de envases el principio de «quien

12 Las externalidades negativas provocadas por la contaminación, su no integración en los mecanismos del mercado como los precios, reveladores de los costes y los beneficios privados y, por tanto, su discrepancia con los valores "verdaderos», ya fueron advertidos en la obra de PIGOU, The Economics of Welfare, en su primera edición de 1920 (citada por Ana YÁBAR STERLING en «Instrumentos Económicos para la protección del medio ambiente», Conferencia Internacional de Derecho Ambiental, Colegio de Abogados de Barcelona, junio de 1995. 
contamina paga», formulado por la OCDE en la Conferencia Internacional sobre Medio Ambiente y Economía de 1986, y recogido ya en 1986 por el Acta Única Europea en el art. $130 \mathrm{R}$ del Tratado.

Lo que, desde el punto de vista económico, caracteriza los modelos de protección del medio ambiente son las diferentes opciones de ineriorización de las deseconomías externas, o costes sociales derivados de la contaminación, y los residuos no son en este sentido una excepción. Esta internalización puede lograrse por dos vías ${ }^{13}$ : la ordenación administrativa de la actividad privada, con la correspondiente fijación de límites, autorizaciones y régimen sancionador y las medidas o incentivos económicos integrados en la economía de mercado. Ambas vías no son antagónicas, sino que pueden complementarse. En realidad, incluso, cuando las medidas económicas son de carácter tributario, o también si se trata de medidas de fomento mediante subvenciones o beneficios fiscales, encajan mejor junto con las medidas administrativas de ordenación, que no entre los incentivos propiamente económicos, entendidos como aquellos que internalizan costes mediante la utilización de mecanismos propios del mercado. De hecho, para la citada declaración de la OCDE de 1984 las dos vías complementarias son, por una parte las medidas administrativas incluidas las fiscales $y$, por otra, los instrumentos económicos integrados en las relaciones del mercado.

Para la OCDE, pues, se trata de complementar la intervención ordenadora, fiscal y subvencionadora del Estado, defendida por Pigou ${ }^{14}$ ya en 1920, con la alternativa más liberal propugnada por Ronald COASE desde $1960{ }^{15}$. Para éste la intervención del Estado en la protección del medio ambiente debe limitarse a asignar correctamente los «derechos de propiedad» sobre la misma contaminación, entre los agentes económicos que la generan, de forma que se establezca un mercado sobre dichos derechos, cuyos precios pasarían así a internalizarse de forma mercantilmente «natural» en los costes de producción. Un ejemplo claro de «patrimonialización» y de establecimiento de un «mercado de la descontaminación», en orden a su reducción, son las cuotas de contaminación atmosférica, asignadas en 1992 en los Estados Unidos por la EPA (Environnmental Protection Agency), de forma que la industria que pretende contaminar por encima de su cuota ha de adquirir cuotas de otras empresas que, o no tienen ne-

13 T. RosembuJ, «Medidas tributarias de protección: fundamento y naturaleza», en Derecho del Medio Ambiente y Administración Local, Civitas, Madrid, 1996, págs. 733 a 737.

14 Pigou, en obra citada en nota 12.

15 R. H. COASE, «The Problem of Social Costs», Joumal of Law and Economics, Vol. 3, 1960, pág. 34; planteamiento seguido después por P. S. DASGUPTA y G. M. HEAL, Economic Theory of Exhaustible Resources, Cambridge University Press, 1979, pág. 77; y de nuevo COASE, DEMETZ y ouros en The Firm, the Market and the Law, The University of Chicago Press, 1988. 
LOS ENVASES Y E SERVICIO MUNICIPAL DE RECOGIDA ...

cesidad de agotar su asignación — p.ej., porque han invertido en procesos menos contaminantes- o que desaparecen por adquisición de la empresa junto con su cuota $^{16}$.

Por lo que respecta a la fiscalidad ambiental, en el documento «Las ecotasas en los países de la OCDE», 1995, se distingue entre tasas sobre productos envasados tendentes a fomentar los envases reutilizables, que quedan exentos, y los reciclables, bonificados, y penalizar los no reutilizables o que utilicen materiales nocivos; los impuestos sobre materias primas en orden al fomento de materiales reciclados; tasas sobre la disposición final de los residuos, para favorecer la valorización; y sistemas de depósito y consigna con reembolso del importe a la devolución del envase. Este último instrumento ya no sería propiamente fiscal sino que, junto a los sistemas de financiación privada del estilo del «punto verde» alemán o francés, formaría parte de los instrumentos económico-mercantiles.

Pues bien, las normativas europeas que han precedido a la Ley española de Envases, y a partir de las cuales la Unión Europea estableció la Directiva $94 / 62 / \mathrm{CE}$, se caracterizan por la forma en que han combinado las medidas de intervención administrativas y las económicas, ya sean de mercado o fiscales. En general y siguiendo a Alemania, la opción mayoritaria es la de la patrimonialización de los residuos de envases con la consiguiente responsabilidad y gestión privada, frente a la más clásica de un gravamen fiscal, únicamente adoptada por Bélgica. El de Francia sería un modelo intermedio en el que, con sustanciales diferencias, se inspira la Ley española ${ }^{17}$. Pasaremos, pues, a un muy rápido examen de las características más distintivas de los ordenamientos alemán, francés y belga.

\subsection{Alemania}

A la vista del resultado de la reglamentación de los envases de bebidas, así como de la constatación de la parcialidad de regular únicamente esta clase de envases, Alemania inició una política más integral de gestión de envases, con la aprobación del Reglamento Federal de 12 de junio de 1991, conocido como

\footnotetext{
16 Una valoración de este sistema, D. MALIN ROODMAN, «Sacar partido al mercado en favor del medio ambiente», en El estado del mundo 1996, Centro Unesco de Cataluña, edición en catalán, Barcelona, 1996, pág. 197.

17 Estudios comparados sobre la normativa de los distintos Estados de la Comunidad Europea, en materia de envases, C. PAÑos CALLADO, Panorama legislativo en países europeos sobre residuos de envases, SOIVRE, Ministerio de Comercio y Turismo, Alicante, 1995; y TH. DEMEY; J. P. HANNEQUART y K. LAMBERT, L'Europe des emballages. Une directive à l'épreuve de 15 transpositions, Institut Bruxellois pour la Gestion de l'Environnement, Bruselas, 1996.
} 
la Ordenanza Töpfer, en plena vigencia desde el 1 de enero de 1993. Esta norma opta por la decidida responsabilización de fabricantes, envasadores y comerciantes en la recogida y el reciclado de envases, agrupados en el «Dual System Deutchland, GMBH», DSD, financiado con aportaciones de las empresas agrupadas que distinguen sus productos con el conocido «grumner punkt» o «punto verde». El sistema privado de financiación, a su vez, implica que el precio de los envases del DSD se incrementa con una cantidad, a título de depósito, que se percibe a lo largo de todo el proceso de fabricación, envasado y comercialización, hasta llegar al consumidor final. El sistema dual alemán se caracteriza, pues, por la asunción por parte de las empresas de la responsabilidad de recogida selectiva y del reciclaje, con independencia del servicio público a cargo de los Kreise (entidades locales supramunicipales de ámbito comarcal) o de la Administración municipal de las grandes ciudades. En todo caso, las entidades locales se han de hacer cargo, mediante contraprestación, de la incineración o depósito de los envases que el sistema privado no puede reciclar. Junto al Dual System, se han creado en Alemania otras agrupaciones empresariales que asumen la recogida y el reciclado de otros envases no incluidos en el DSD, como por ejemplo el GROW para envases de madera, o el VRDS, el RVT, el Resy o el Interseroh.

\subsection{Bélgica}

Bélgica ha optado por la vía de la fiscalidad, mediante el establecimiento de una ecotasa sobre buena parte de los embalajes y los envases, de la que quedan exentos los envases que son objeto de recogida mediante un sistema de depósito y consigna, así como los que alcanzan determinados objetivos de reutilización y de reciclaje a cargo de los envasadores ${ }^{18}$. Este tributo estableció en la Ley de 16 de julio de 1993, modificada por las Leyes de 3 de junio de 1994 y 9 de febrero de $1995^{19}$.

\subsection{Francia}

Poco después del Reglamento alemán, Francia a iniciativa del entonces Ministro de Medio Ambiente, Brice Lalonde, aprobó el Decreto 377/1992, de 1

18 E. ORBAN DE XIVRY, «Les écotaxes au regard du droit des déchets», en L'introduction des écotaxes en Droit belge, Facultés universitaires Saint-Luis Bruxelles, Bruselas, 1994, págs. 177 a 187.

19 Más que una écolaxe, este tributo es más bien una écorédévance, puesto que la expresión taxe, en Derecho tributario francés y belga, se utiliza para referirse a impuestos indirectos - p.ej., la Taxe sur le Valeur Ajouté, TVA- mientras que la rédévance se corresponde más propiamente a la tasa del Derecho tributario español. 
de abril ${ }^{20}$. La norma francesa, aunque se base también en la corresponsabilización y agrupación del sector privado, a través de Eco-Emballages, S.A., se diferencia del sistema alemán en tres relevantes aspectos:

a) El objetivo ambiental no es el reciclaje sino, con carácter más general la recogida y la «eliminación» de los residuos de envases, entendida la eliminación en un sentido amplio que comprendería el depósito en vertedero, la incineración con recuperación de energía o sin ella, y el reciclaje de materiales.

b) La recogida selectiva y la clasificación de los residuos de envases corre a cargo de los servicios públicos de las entidades locales — normalmente syndicats o mancomunidades- cuyos gastos son retribuidos por Eco-Emballages. La participación de los entes locales no es pues voluntaria, sino un claro mandato legal; este aspecto es de sustancial importancia para cuando pasemos al estudio de la forma de participación de los entes locales en los sistemas integrados de gestión, regulados en la Ley española de Envases.

c) La valorización y la eliminación de los residuos las asume y financia el sector privado, ya sea directamente o contratando el servicio a terceros. Esta gestión privada del tratamiento incluye tanto el reciclaje como la incineración y el depósito en vertederos, aunque estas dos últimas operaciones se contratan habitualmente con las propias entidades locales.

La identificación de las empresas agrupadas en Eco-Emballages se efectúa mediante un «punto verde» idéntico al alemán, que también implica que el precio del producto está incrementado con una determinada cantidad con la que se financia el coste del sistema, incluidas las contraprestaciones a las colectividades locales.

\section{LA DIRECTIVA 94/62/CE}

En este contexto, la Comisión Europea, al amparo del art. 100 A del Tratado ${ }^{2 !}$, impulsó una propuesta de Directiva sobre envases y residuos de envases, presentada el 24 de agosto de 1992 . El proceso fue largo y complejo, tanto por las diferentes posiciones de los Estados miembros, como por los efectos de la

20 Sobre esta norma , C. PAÑos CALlado, «El Decreto Francés de Eliminación de Envases Domésticos: Solución Eco-Emballage», Cuadernos de Información SOIVRE, Ministerio de Comercio y Turismo, 13, Alicante, 1993.

21 Aunque se trate, pues, de una Directiva de armonización, el propio art. $100 \mathrm{~A} .3$ advierte que, si el objeto de la norma afecta al medio ambiente, la propuesta de la Comisión ha de exigir un alto nivel de protección, con lo que en la práctica la Directiva adquiere un contenido ambiental expreso y directo. 
entrada en vigor, el 1 de noviembre de 1993, del Tratado de la Unión Europea y la aplicación del procedimiento de codecisión entre el Consejo y el Parlamento Europeos, establecido en el art. $189 \mathrm{~B}$ del Tratado. El proceso de redacción de la directiva se vio asimismo influido por el V Programa Comunitario de Política Comunitaria y Actuación en Materia de Medio Ambiente y Desarrollo Sostenible, de 1 de febrero de 1993, cuyo epígrafe 5.7 se dedica en particular a la gestión de residuos. Finalmente, esta iniciativa se convirtió en la Directiva 94/62/CE, del Parlamento y del Consejo, de 20 de diciembre de 1994.

Sucintamente, la referida Directiva sobre Envases y Residuos de Envases establece los siguientes objetivos y obligaciones de los Estados miembros:

a) Prevención ${ }^{22}$, sin objetivos definidos en cuanto a la reducción de la cantidad o peso de los envases, pero sí de su nocividad respecto de los límites de concentración de metales. Los Estados miembros son pues libres de fijar sus propios objetivos de prevención en la transposición de la Directiva y, sobre todo en la planificación que, en aplicación de su art. 14 aprueben.

b) Objetivos, a 5 años, de entre el $50 \%$ y el $65 \%$ en peso ha de ser objeto de valorización, de la que entre $25 \%$ y un $45 \%$ ha de ser mediante reciclaje con un mínimo del $15 \%$ de reciclado de cada material. Los objetivos de la propuesta original de agosto de 1992 eran mucho más ambiciosos - 60\% de valorización, a los cinco años, y $90 \%$ con $60 \%$ el de reciclaje y el $10 \%$ de disposición final, a los diez años - han desaparecido. En su lugar, se habilita al Consejo para que, transcurrido ese plazo, revise los porcentajes de valorización y reciclado. En todo caso, no se mantiene alusión alguna a un límite máximo de eliminación o disposición final; la explicación está tanto en la importancia que tienen los vertederos en Europa, como a la progresiva valoración positiva que va adquiriendo el vertedero controlado, frente a la valorización energética mediante incineración.

c) Una relativa jerarquización, derivada de los objetivos, por el siguiente orden de prelación: $1 .^{\circ}$ reciclaje, $2 .^{\circ}$ valorización con recuperación de energía incluida la incineración, y depósito en vertedero controlado, que viene a coincidir con la jerarquización que establece el art. 3 de la Directiva 75/442/CEE$91 / 156 / \mathrm{CEE}^{23}$. El pronunciamiento sobre la prelación entre la reutilización y el reciclaje se deja para más adelante, a la espera de los resultados dè los estudios

\footnotetext{
22 En lugar de «prevención», la Ley catalana 6/1993 utiliza la expresión «minimización», para referirse a las acciones tendentes a la reducción del número, del peso y de la nocividad de los envases y de sus residuos.

23 Sobre la cuestión de la jerarquía de los tratamientos, DEMEY, HANNEQuART y LAMBERT, L'Europe des emballages. Une directive ..., op. cit., págs. 14 a 17.
} 
LOS ENVASES Y EL SERVICIO MUNICIPAL DE RECOGIDA ...

científicos y técnicos sobre el ciclo de vida de los materiales. Decimos que la jerarquización es relativa porque el margen de porcentajes permite diferentes combinaciones: en el extremo más «conservador» $50 \%$ de vertido, $25 \%$ de reciclaje y $25 \%$ de incineración con recuperación de energía, en el extremo más «ecológico» $45 \%$ de reciclaje, $20 \%$ de incineración con recuperación energética y $35 \%$ de vertido, y en el «centro» $40 \%$ de incineración con recuperación de energía, $25 \%$ de reciclaje y $35 \%$ de vertido.

d) Establecimiento de sistemas de devolución o de recogida selectiva de los envases usados o de los residuos de envases, de reutilización y de valorización, incluido el reciclaje, con participación de los agentes económicos, de los sectores afectados y de las Administraciones competentes ${ }^{24}$. Junto con el de los instrumentos económicos, con los que guarda estrecha relación, este punto sufrió también importantes modificaciones. En la propuesta de la Comisión agosto de 1992, se estipulaba que los Estados debían adoptar medidas para establecer sistemas que garantizasen «el retorno de todos los envases usados y/o de todos los residuos de envases», y en el texto modificado en cooperación con el Parlamento se mantiene esta referencia unívoca al retorno. Sin embargo, en la posición común del Parlamento y el Consejo de marzo de 1994 se modifica la expresión «retorno» por la de «devolución», pero lo significativo es que se añade la recogida como operación alternativa a la devolución, de forma que el texto adopta ya su actual contenido de «devolución o recogida de los envases usados o de residuos de envases». Es evidente pues que con la primera redacción la Comisión, y luego el Parlamento, apostaban por un modelo general y único de consigna, depósito y devolución, tanto para los envases usados reutilizables como para los residuos en envases destinados al reciclaje de materiales. El objetivo de este modelo era congruente con los ambiciosos objetivos de retirar del flujo de residuos de envases y, sobre todo de su disposición final, primero el $60 \%$ a los cinco años y el $90 \%$ a los diez. Sin embargo, la consecuencia era obvia: el sistema dual alemán y los sistemas semejantes adoptados por otros Estados miembros tendría que ir sustituyendo, progresivamente, la recogida selectiva en contenedores ubicados en la vía pública, por un sistema de depósito con el retorno, en los establecimientos comerciales, tanto de los envases usados como los residuos de envases, y la consiguiente devolución del importe del depósito que tuvo que abonar en el momento de la compra, salvo que, claro está, al mismo tiempo que devuelve un envase usado o residuo de envase adquiera un producto envasado de las mismas características. En definitiva, se trataba de extender a toda clase de envases la práctica habitual en la comercialización de bebidas en envases de vidrio, retornables y reutilizables. El resultado final de este modelo era, evidentemente, la práctica supresión de los residuos de enva-

24 Sobre reutilización DEMEY, HANNEQUART y LAMBERT, L'Europe des emballages. Une directive ..., op. cit., págs. 97 a 116. 
ses del sistema público de recogida, tratamiento y disposición final, expresada en el objetivo del $90 \%$ a los diez años de vigencia de la Directiva. Este sistema además se encuadraba claramente en una clara vía de patrimonialización y mercantilzación de la contaminación generada por los productos envasados, puesto que atribuía un valor a los envases usados o a sus residuos. El usuario se vería así económicamente motivado a la devolución, y los envasadores y comerciantes tendrían el incentivo, igualmente económico, de reducir el peso y el volumen los envases, puesto que las deseconomías externas transferidas sin coste a la Administración, se internalizaban en sus gastos logísticos. Era - y es- la gran solución a la que, en cualquier caso no hay que renunciar puesto que está contemplada tanto en la Directiva como en la Ley española de envases.

e) Planificación pública, como instrumento administrativo de intervención en la actividad privada (art. 14 de la Directiva 94/62/CE, por remisión al art. 7 de la Directiva 75/442/CEE modificado por la 91/156/CEE).

f) Se trata de una de las primeras Directivas comunitarias que prevé el establecimiento de medidas económicas -y además comunes - como instrumentos de política de protección del medio. En realidad sería la primera, si no contáramos la Directiva 92/81/CEE que prevé bonificaciones para la gasolina sin plomo. En la Directiva sobre envases y residuos de envases se dispone que, en un futuro no determinado, el Consejo Europeo deberá establecer instrumentos económicos comunes a todos los Estados miembros; ahora bien, mientras el Consejo no los establezca, cada Estado puede aprobar los suyos propios, basándose en los principios del Derecho comunitario y, entre otros, en el de «quien contamina paga». La regulación de las medidas económicas, recogida en el art. 11 de la Directiva, fue especialmente controvertida en el largo proceso de aprobación. En la redacción original de la Comisión, el establecimiento de instrumentos económicos para fomentar los objetivos de la Directiva se remitía a la voluntad de los Estados miembros. En la propuesta modificada del Consejo, en cooperación con el Parlamento Europeo, presentada el 9 de septiembre de 1993, el establecimiento de los instrumentos económicos ya aparecía como una obligación del Consejo, aunque indefinida en el tiempo; y, en ausencia de normas comunitarias, se autorizaba a los Estados a aprobar sus propios medidas. En todo caso, se fijaban unas reglas generales: nexo claro entre las medidas y los objetivos, no discriminación de envases y de materiales, gestión ágil que no precise una administración excesiva, y respeto del principio de «quien contamina paga». La fijación de estos criterios y, en particular, el relativo a la gestión administrativa, preocupó a Bélgica, que veía peligrar su régimen tributario sobre los envases. En la posición común del Consejo y el Parlamento, adoptada el 4 de marzo de 1994, se volvía simplemente a la redacción original. Y finalmente, en el texto definitivo se impuso la propuesta de 1993, sin 
mención a los criterios que tanto preocupaban a los belgas, salvo la alusión obvia al principio de contaminador-pagador ${ }^{25}$.

g) Obligaciones de información tanto de los agentes económicos para con los usuarios y las Administraciones competentes, como de los Estados para con la Comisión Europea ${ }^{26}$. En cumplimiento de la Directiva y a principios del pasado año 1997, la Comisión ha adoptado la Decisión 97/129/CE, de 28 de enero, sobre el sistema de identificación voluntaria de los distintos materiales de envasado y la Decisión 97/138/CE, de 3 de febrero, sobre modelos relativos al sistema de bases de datos para el suministro de información.

h) Finalmente, obligación de los Estados miembros de transponer la Directiva 94/62/CE a su Derecho interno, antes del 30 de junio de 1996.

\section{LA TRANSPOSICIÓN ESPAÑOLA: LA LEY DE ENVASES Y RESIDUOS DE ENVASES DE ABRIL DE 1997}

Con casi un año de retraso sobre la fecha exigida, se aprobó la transposición española de la Directiva 94/62/CE, mediante la Ley 11/1997, de 24 de abril. Como el de la Directiva, su proceso de aprobación fue largo y tortuoso, tanto en la fase de redacción de borradores - 14 ó 15- como en la de aprobación del Proyecto en el Consejo de Ministros, y de la Ley en el Congreso y en el Senado. La Ley $11 / 1997$ ha sido objeto de desarrollo y ejecución mediante el Reglamento aprobado por el Real Decreto 782/1998, de 30 de abril.

En relación con la Directiva, la Ley de Envases se puede dividir en las siguientes partes: objetivos generales, objetivos de prevención, objetivos de valorización, sistema general de depósito, sistemas de gestión privada y participación de las entidades locales, intervención de las Comunidades Autónomas, instrumentos económicos, planificación y programación, información, y régimen sancionador.

\subsection{Objetivos generales}

La Ley señala, en su art. 1.1, unos objetivos generales entre los que destaca la jerarquización $\mathrm{u}$ orden de prioridad de las distintas acciones y tratamientos a seguir. Este orden sigue, fielmente, el fijado en el art. 3 de la Directiva general de residuos 75/442/CEE-91/156/CEE, con la prevención de producción de re-

\footnotetext{
25 Sobre los instrumentos económicos DEMEY, HANNEQUART y LAMBERT, L'Europe des emballages. Une directive ..., op. cit., págs. 117 a 137.

26 Sobre información DEMEY, HANNEQUART y LAMBERT, L'Europe des emballages. Une directive ..., op. cit., págs. 75 a 93 .
} 
siduos de envases en primer lugar. Pero a continuación y antes del reciclado, se sitúa la reutilización, adelantándose así la Ley española a la cautela de la Exposición de Motivos de la Directiva $94 / 62 / \mathrm{CE}$, en la que - como ya se ha avanzado- la priorización del reciclaje o la reutilización se deja para más adelante, a la espera de los resultados de los estudios sobre el ciclo de vida de los materiales. Siguen, a continuación, el reciclado y las demás formas de valorización, incluida por tanto la incineración con recuperación energética, quedando en último término la eliminación o disposición final, de la que se dice que debe evitarse o reducirse. Aunque ya hemos visto que los objetivos porcentuales de la Directiva, reproducidos por la Ley, permiten hasta el $50 \%$ de disposición final, o hasta un $40 \%$ de valorización por incineración con recuperación de energía; es decir, en ambos casos por delante del reciclaje que se puede limitar al $25 \%$.

\subsection{Objetivos de prevención}

Los objetivos de prevención cualitativa, que tienen por objeto la reducción de la nocividad y referidos a la concentración de metales en los materiales de los envases, son los mismos de la Directiva, y así el art. 13.1 de la Ley contempla para el 1 de julio del 2001 una concentración no superior a 100 ppm. La innovación y mejora de la Ley española está en el objetivo de prevención cuantitativa - no exigido por la Directiva- que, en el art. 5 c) y para el 30 de junio del 2001 se fija en una reducción del $10 \%$, en peso, de la totalidad de los residuos. Por otra parte, el hecho de que la reutilización aparezca en el art. 1.1 de la Ley con prioridad sobre el reciclaje y las otras formas de valorización, aunque sin objetivos precisos, implica una vía de reducción de los residuos de envases derivada del retardamiento del paso del envase a residuo de envase. Y tampoco debe perderse de vista que el adecuado desarrollo de las previsiones de la Ley 21/1992, de 16 de julio, de Industria, ha de permitir la eliminación o la disminución de los componentes nocivos con los que los envases son fabricados y el fomento del uso de materiales que favorezcan la reutilización de los envases usados y el reciclaje de los residuos de envases ${ }^{27}$.

\subsection{Objetivos de valorización y de reciclaje}

Los objetivos de valorización y reciclaje del art. 5 de la Ley española reproducen los mismos márgenes porcentuales que el art. 6 de la Directiva; es decir, entre el $50 \%$ y el $65 \%$ de valorización incluida la incineración con recupera-

27 Sobre la Ley de Industria y sus implicaciones con la Administración local, ver E. MALARET; M. ${ }^{2}$ M. PÉREZ y J. CONDE, «La regulación municipal de medio ambiente y la industria», en la obra colectiva citada Derecho del Medio Ambiente y Administración Local. Diputación de Barcelona/Civitas, 1996, págs. 146 a 148. 
ción de energía con entre un $25 \%$ y un $45 \%$ de reciclado que, como mínimo, ha de alcanzar al $15 \%$ de cada material, todo ello siempre en peso. Lo propio de una transposición al Derecho interno de una Directiva comunitaria, cuando ésta plantea unos objetivos mínimos y otros máximos, es que la norma estatal efectúe una opción concreta reduciendo los márgenes, ya sea en menos o en más. Así, por ejemplo, para que la Ley fuera coherente con el objetivo general de su art. 1.1 de evitar o reducir la eliminación o disposición final, el porcentaje mínimo de valorización debiera ser superior al 50\%; y si, de acuerdo con ese mismo precepto, el reciclaje de los envases ha de tener prioridad sobre las demás formas de valorización -la incineración con recuperación energética, básicamente - el porcentaje mínimo de reciclado debiera haber pasado del $25 \%$ de la Directiva al 33\%, para así ser superior al 32\% restante del peso de los residuos de envase que, como máximo, podría ser incinerado. En todo caso, los objetivos de la Ley siempre son susceptibles de mayor concreción, conforme a lo previsto en el art. 17, por los Programa autónomicos y por el Programa Nacional de Residuos de Envases Usados en los que aquellos se han de integrar. De todas formas, la Ley contiene dos mejoras en relación con la Directiva: la previsión de que los materiales que, a 30 de junio del 2001, no hayan conseguido un reciclaje del $15 \%$, podrán ser objeto de gravamen fiscal; y el objetivo intermedio, a los tres años, de reciclar el $15 \%$ en total y, como mínimo, el $10 \%$ de cada tipo de material.

\subsection{Sistemas de gestión de los envases usados y de los residuos de envases}

Hasta ahora, el estudio, la interpretación y las previsiones de futura aplicación de la Ley de Envases y Residuos de Envases se ha tendido a efectuar a partir de la idea de que el sistema de gestión ordinaria estará a cargo de los envasadores y comerciantes, organizados en entes gestores de sistemas integrados con la participación de las Entidades Locales y la intervención de las Comunidades Autónomas. Descartada la opción de establecer como único o preferente el sistema de depósito, devolución y retorno, es cierto que con toda probabilidad, ése va a ser el modelo de gestión que se va a imponer de forma generalizada en España. Pero lo que no se puede hacer es entender que la Ley tiene únicamente por objeto ese sistema de gestión, porque - como veremosde esta actitud interpretativa se pueden derivar resultados aplicativos no ajustados a Derecho y, además, considerablemente perjudiciales para las haciendas municipales.

En la regulación de la gestión de los envases y sus residuos, la Ley española parte de la opcionalidad y la compatibilidad entre un sistema de devolución y un sistema de recogida selectiva que ya hemos visto que permite la Directiva 
94/62/CE. Sin embargo, la Ley española no hace lo que sería propio de una transposición; es decir, a partir del régimen abierto de la Directiva comunitaria, establecer y regular modelos de gestión en función de los distintos materiales con los que pueden estar manufacturados los envases, de las características de los productos envasados o del tipo de establecimiento en el que se comercializan. Por el contrario, nuestra Ley de Envases traslada a envasadores y comerciantes la libre elección del sistema de gestión de sus envases. Las opciones contempladas por la Ley son dos: el sistema de depósito, devolución y retorno en los establecimientos comerciales, y los sistemas integrados de gestión a partir de la recogida selectiva de los residuos de envases en el domicilio del consumidor o en sus proximidades. La segunda modalidad permite las variantes ya aludidas, consistentes en la participación de las entidades locales, con la intermediación de las Comunidades Autónomas en esa participación local, que en realidad es la opción por la que apuesta el legislador.

\subsubsection{Sistemas de depósito, devolución y retorno}

De acuerdo con el art. 6 de la Ley 11/1997, el sistema de depósito, devolución y retorno es, en principio, el de aplicación general y obligatoria a la gestión de los envases y residuos de envases. Según este precepto, la responsabilidad sobre los envases y sobre los residuos de envases se traslada a los industriales envasadores y a los comerciantes de productos envasados o, cuando no sea posible identificarlos, a los responsables de la primera puesta en el mercado de los productos envasados. Esta responsabilidad alcanza también a los titulares de máquinas expendedoras automáticas y de empresas de venta por correo. Se pretende con ello que estas empresas se hagan cargo de los envases usados y de los residuos de envases, de su posterior reutilización y tratamiento, así como de alcanzar los objetivos de reciclaje y valorización fijados en la Ley y, en su caso, concretados en los Programas autonómicos y en el Programa Nacional de Envases y Residuos de Envases. Para ello los agentes económicos antes citados tienen para con los envases y sus residuos un régimen de obligaciones sucesivas, equivalente al que, de forma natural, el propio mercado tiene establecido para los envases retornables y reutilizables, como los de vidrio para bebidas o las bombonas de gas. Es decir:

a) En primer lugar, los envasadores, empresas de venta automática mediante máquinas expendedoras y de ventas por correo o, en su caso, los responsables de la primera puesta en el mercado del producto envasado, deben identificar sus envases de forma que se distingan de los envases acogidos a los alternativos sistemas integrados de gestión. Tratándose del sistema, en principio, general y ordinario, esta obligación debería serlo simplemente de identificar, mientras que la preocupación de que su identificación se distinguiera de la 
del sistema de depósito debería recaer en los sistemas integrados, alternativos al de depósito. Los comerciantes, además, pueden añadir una identificación propia, con el fin de poder aceptar, únicamente, la devolución de los envases de los productos comercializados en sus establecimientos.

b) Los referidos agentes, desde el envasador hasta el establecimiento comercial que vende el producto envasado al consumidor final, han de percibir una cantidad por cada envase que se objeto de transacción. El importe de estas cantidades ha sido fijado por el Ministerio de Medio Ambiente por Orden de 27 de abril de 1998. Inicialmente, se especificaba que, a efectos mercantiles y fiscales, esta cantidad no tenía la consideración de precio, ni estaba sujeto a ningún tributo, lo que en particular expresaba que no estaba sujeto a la cuota del IVA que grava el precio del producto envasado; sin embargo, de la nueva redacción que la Disposición Adicional 11. ${ }^{a}$ da al art. 6.1 de la Ley de Envases se desprende, justamente, todo lo contrario. Ahora bien, si esa cantidad está sujeta a IVA cuando es devuelta en el momento de que el usuario retorna el envase al comerciante al que se lo ha adquirido o a otro distinto, la gestión de ese IVA parece que va a ser harto compleja. En otro orden, el importe de esta cantidad no es de fácil fijación, puesto que, por una parte, ha de ser lo bastante elevada para que incentive la devolución del envase, pero tampoco puede tan cuantiosa que disuada el consumo. Por lo que respecta a su naturaleza jurídica, se trataría de un depósito impropio, en la medida que no responde a ninguna de las modalidades de depósito de cosa mueble o de dinero, de los arts. 1758 a 1784 del Código Civil, aunque en todo caso sí que sería un depósito necesario, dado que se hace en cumplimiento de una obligación legal, tal y como contemplan los arts. $1781.1 .^{\circ}$ y 1782 , con remisión a las disposiciones de la ley en cuestión. Lo que está claro es que el vendedor del producto envasado, más allá del deber de devolver la cantidad percibida cuando su cliente devuelva el envase, no tiene una especial obligación con respecto a la custodia y uso de la masa de dinero que en su economía genera esta práctica ${ }^{28}$.

c) Los comerciantes han de aceptar la devolución, por parte del público en general, de los envases usados o de los residuos de envases, siempre que se trate del mismo tipo, formato y marca que comercializan, tanto si se han vendido en su establecimiento como en otro distinto; por el contrario pueden, e incluso deben, rechazar el retorno de envases de tipos, marcas o formatos distintos. Ahora bien, si, como hemos visto, además de la identificación general, los comerciantes han identificado los envases por ellos mismos puestos a la venta, pueden limitarse a aceptar éstos y rechazar todos los demás, aunque sean de la misma marca, tipo y formato, pero vendidos en otros establecimientos. Los co-

28 Como asimismo ya ha quedado claro que no tenía especiales obligaciones el canal de televisión codificada, por las cantidades percibidas, en depósito, por los aparatos descodificadores. 
merciantes, a su vez, devolverán los envases y los residuos de envases a los distribuidores o mayoristas hasta llegar a los envasadores. Los envasadores sólo están obligados a aceptar los envases y residuos de envases puestos por ellos en el mercado. En el momento de la devolución, tanto comerciantes como envasadores deben, a su vez, devolver la misma cantidad que habían percibido con ocasión de la venta del producto envasado.

d) Los envasadores o cualquier otro poseedor final de la cadena de devolución debe entregar los envases y residuos de envases, en condiciones adecuadas de separación por materiales a un agente económico para su reutilización - normalmente el propio envasador - o bien a un agente autorizado para su reciclaje u otra forma de valorización. Si ello no es posible, la entrega puede hacerse a los fabricantes, importadores o adquirentes de envases y materias primas para su fabricación, en otros Estados miembros de la Unión, tal y como especifica el segundo párrafo del art. 12 de la Ley.

e) Quedan excluidos del sistema de depósito los envases industriales y los comerciales, los poseedores de los cuales vienen obligados por la Disposición Adicional Primera 1 de la Ley 11/1997 a entregarlos a empresas de reciclaje, en aplicación del art. 12 de la misma Ley; ello sin perjuicio de que, voluntariamente, los responsables dichos envases decidan someterse al sistema de depósito o al de los sistemas integrados de gestión. El Reglamento de Ley atribuye el control de la gestión de los envases industriales y comerciales a las Comunidades Autónomas.

f) Este sistema puede establecerse con carácter obligatorio $-\mathrm{y}$, por tanto, sin la opción alternativa de los sistemas integrados- para ciertos envases y residuos de envases, en función de peligrosidad o toxicidad de su composición química o de los productos que han contenido (pinturas, disolventes, etc.). La determinación de estos supuestos se desplaza a la vía reglamentaria, que tanto podrá ser ejercida por el Estado, como por las Comunidades Autónomas, sobre todo a la vista de que el Reglamento no regula este aspecto.

Como se puede advertir, la regulación del sistema de depósito es muy clara pero, a la vez, muy simple. Si realmente éste fuera el modelo de gestión a implantar a buen seguro que la regulación sería mucho más precisa. Así, debería regularse el cumplimiento por parte de los envasadores de los objetivos de valorización y reciclaje; la intervención en el control del sistema por parte de las entidades locales; así como contemplarse el supuesto de los residuos de envases que - a pesar de la pérdida del importe del depósito- pueden ser abandonados por los consumidores, obligando al servicio municipal a su recogida. $\mathrm{Si}$ estos extremos u otros no están previstos en la Ley es porque el legislador no 
LOS ENVASES Y EL SERVICIO MUNICIPAL DE RECOGDA ...

tiene la voluntad decidida de que esta sea la vía de aplicación de las previsiones de la misma norma.

Es evidente que el sistema de depósito y devolución, de implantación obligatoria, sería la gran solución al difícil problema, de gestión y de financiación, que para la Administración local ha generado el creciente incremento del peso y el volumen de los residuos municipales por causa de los envases. En realidad, lo que hace el sistema de depósito es liberar al servicio municipal -en sentido estricto o prestacional - de la recogida, el tratamiento y el aprovechamiento de los residuos de envases, cuya gestión pasa a ser responsabilidad de los industriales envasadores y de los comerciantes. Se trataría de una auténtica «devolución» de la responsabilidad sobre los residuos de envases a los agentes económicos que los generan y de los que, al amparo del servicio público local, se habían desentendido absolutamente. Difícilmente encontraríamos un ejemplo más claro de interiorización por la vía de la patrimonialización de los costes sociales provocados por una forma de contaminación y de los mecanismos de mercado ${ }^{29}$, según hemos visto que han propugnado COASE, DASGUPTA, DEMETZ y otros autores de la escuela de Chicago. Por otra parte, la efectividad el principio de «quien contamina paga» se consigue de forma tendencialmente absoluta.

Ahora bien, desde una perspectiva europea ajustada al emergente Derecho comunitario sobre servicios públicos o servicios económicos de interés general ${ }^{30}$, esta devolución de la responsabilidad al sector privado no implica que la gestión de los envases y residuos de envases deje de constituir un servicio público. Así es, el sistema de depósito encaja pacíficamente en una conceptuación sustantiva de servicio público que, superada la concepción subjetiva que necesariamente atribuye la prestación a la Administración, permite que la misión de servicio público se encomiende o atribuya al sector privado. La Administración se reserva la función de garantizar, regular y controlar la actividad del operador o operadores privados ${ }^{31}$. Esta función reguladora es especialmente intensa en el caso que nos ocupa, puesto que para los envasadores y comerciantes la misión de servicio público es una obligación que, por mandato de la Ley, se incorpora a la actividad empresarial propia de estos subsectores. Quizá lo característico de la gestión privada del servicio público de recogida y tratamiento de envases y residuos de envases es el carácter obligatorio de la misión

29 Entre ellos, el interés de los consumidores en recuperar la cantidad que han dejado en depósito, o de no verse obligados a volverla a dejar cuando adquieren de nuevo un producto envasado.

30 COMision Europea, «Los servicios de interés general en Europa», DOCE, núm. C-281/3, de 11 de septiembre de 1996; CH. STOFFAES y AA.VV., «L'Europe à l'épreuve de l'intérêt général», ASPE, París, 1994; L.GrARD y AA.VV., "Vers un service public européen», ASPE, París, 1996.

31 E. MALARET, «Servicios, públicos, funciones públicas, garantías de los derechos de los ciudadanos: perennidad de las necesidades, transformación del contexto", $R A P, \mathrm{n}^{\circ}{ }^{\circ} 145,1998$. 
de servicio público que se atribuye a los agentes económicos, mientras que en otros servicios públicos confiados a privados esta obligatoriedad no abarca todo el servicio, sino únicamente aquellos aspectos del mismo que se califican de universal por las exigencias de interés general que los caracteriza que, en nuestra Constitución, estarían directamente vinculados a principios rectores de la política económica y social $o$, incluso, a derechos y libertades fundamentales ${ }^{32}$.

Por lo que se refiere a la titularidad de los residuos de envases, no cabe duda de que, en el sistema de depósito, nunca llegan a ser patrimonio municipal, sino que el envasador mantiene $-o$ recupera si se prefiere- la titularidad sobre los envases cuando le son devueltos. Ello sin perjuicio, claro está, de que el consumidor puede retener indefinidamente la posesión del envase o bien abandonarlo, a costa de perder la cantidad que ha dejado en depósito. Sólo en caso de abandono, el residuo de envase pasará, como res derelicta, a ser un bien patrimonial del municipio, una vez recogido ya sea por el servicio de residuos o por el de limpieza de la vía pública.

Esta formulación cede, sin embargo, cuando el legislador permite la opción alternativa de los envasadores y comerciantes de acogerse a los sistemas integrados de gestión, que eximen del más riguroso sistema de depósito ${ }^{33}$. En realidad, pues, el sistema de depósito no se plantea en la Ley como un sistema realmente operativo, sino como un presupuesto a partir del cual, por la vía de la excepción y de la exención de las obligaciones del sistema de depósito, se establecerán los sistemas de gestión realmente operativos que van a ser los llamados integrados y, en particular, los que cuenten con la participación de las Entidades Locales y la intervención e intermediación de las Comunidades Autónomas. En cualquier caso, no se puede perder de vista que el sistema de depósito es la regla general de la ley, y que los sistemas integrados, en sus diversas modalidades, son excepciones a esa regla general.

\subsubsection{Los sistemas integrados de gestión de envases y residuos de envases}

De acuerdo con el art. 7.1 de la Ley, los envasadores, comerciantes y demás implicados en el sistema de depósito y devolución pueden eximirse de las obli-

32 Sobre el servicio universal, S. MuÑoz MACHADo, Servicio público y mercado, Vol. I, Civitas, Madrid, 1997, págs. 317 a 324; E. MALARET, «Servicios públicos, funciones públicas, garantías de los ciudadanos ...», op. cit.

33 Hay que advertir que el establecimiento del sistema de depósito, como general y obligatorio afectaría, de forma notable a la comercialización, tanto en los pequeños comercios, como en las grandes superficies que tampoco acostumbran a habilitar espacios amplios para el almacenamiento. Precisamente, en el Proyecto de Ley de Envases aprobado por el Gobierno se autorizaba a las Comunidades Autónomas a establecer como obligatorio el sistema de depósito para las grandes superficies comerciales, presión que desapareció en el debate parlamentario. 
gaciones del mismo si se incorporan a un «sistema integrado de gestión de envases y residuos de envases derivados de los productos por ellos comercializados». Esta incorporación libera también a los agentes económicos del cumplimiento individual de los objetivos de reciclaje y valorización que son asumidos por el «sistema integrado».

Los «sistemas integrados» se han de constituir en personas jurídico-privadas sin ánimo de lucro. Se trata por tanto de entidades asociativas que difícilmente pueden tener carácter de sociedades mercantiles ordinarias, lo que nos remite —como figura más idónea- a las agrupaciones de interés económico, reguladas por la Ley $12 / 1991$, de 29 de abril ${ }^{34}$. La creación del sistema integrado ha de ser autorizada por cada Comunidad Autónoma, de lo que se deduce que su ámbito territorial será inevitablemente autónomico, sin perjuicio que un sistema integrado estatal pueda ser autorizado por varias o por todas las Comunidades. Los sistemas integrados pueden tener por objeto distintos tipos de envases, y por tanto integrar un espectro amplio de envasadores y comerciantes, o bien dedicarse a determinados envases (vidrio, cartón, brics, etc.) en cuyo caso los socios del ente gestor serán, esencialmente, fabricantes y envasadores de un mismo subsector. En todo caso, la Ley prohíbe que se asocien al sistema integrado las organizaciones de consumidores y usuarios, las entidades locales $u$ otra clase de Administración pública. La autorización es temporal, por cinco años, renovable por idéntico período, pero no puede transmitirse a terceros. En el procedimiento de autorización se prevé la audiencia de las organizaciones de consumidores y usuarios pero, curiosamente, no la de las entidades locales; de todas formas, éstas siempre pueden comparecer y ser parte en el expediente. En aplicación del supuesto f) de los vicios de nulidad de pleno derecho del art. 62.1 de la Ley de Procedimiento Administrativo Común, el art. 8.4 de la Ley de Envases estipula que jamás se podrán entender adquiridas por acto presunto autorizaciones o facultades que contravengan lo establecido en dicha Ley.

Los sistemas integrados y, en particular, las entidades asociativas gestoras de los mismos tienen las siguientes obligaciones:

a) Recoger selectivamente los residuos de envases. De acuerdo con el art. 7.2 de la Ley, la finalidad de los sistemas integrados de gestión es la «recogida periódica de envases usados y de residuos de envases, en el domicilio del consumidor o en sus proximidades». En realidad los envases usados, retornables y

34 La finalidad de las AIE es «facilitar el desarrollo o mejorar los resultados de la actividad de los socios», «no tiene ánimo de lucro para sí misma», y su objeto «se limitará exclusivamente a una actividad económica auxiliar de la que desarrollen sus socios»; han de constituirse mediante escritura pública e inscribirse en el Registro Mercantil; y disfrutan de un régimen fiscal especial. Sorprendentemente, el sistema integrado ECOEMBES - Ecoembalajes España, S.A.- se ha constituido como «sociedad anónima sin ánimo de lucro» (?!). 
reutilizables, serán de los pocos que se acogerán al sistema de depósito y devolución por la sencilla razón que ésta ya es la práctica habitual. Los sistemas integrados ceñirán pues su actividad a los residuos de envases $y$, excepto supuestos muy concretos (bombonas de gas) o para grandes consumidores (restauración, hospitales, etc.), difícilmente la recogida será a domicilio, sino que se hará en contenedores dispuestos en la vía pública. En la recogida hay que incluir lógicamente el transporte hasta los centros de selección y clasificación, de reciclado o de las otras formas de valorización, según el caso.

b) Seleccionar y clasificar los residuos de envases. La selección puede hacerse, parcialmente, en origen y a cargo de la buena voluntad del ciudadano, mediante la recogida selectiva en contenedores diferenciados según el tipo de material (papel y cartón; vidrio y cristal; plásticos, metales y brics), y un posterior proceso de selección y clasificación en una instalación adeucada $\mathrm{O}$ bien, en el sistema húmedo/seco, en el que todos los envases junto a los demás residuos inorgánicos se recogen en un mismo contenedor, con lo que el proceso de ulterior selección es mucho más complejo.

c) Reciclar o valorizar por otros métodos distintos al reciclaje los residuos de envases, cumpliendo los objetivos marcados por la Ley y concretados en los programas autonómicos y en el Programa Nacional. La misma entidad gestora del sistema integrado puede hacerse cargo de estas operaciones de reciclado o valorización, o bien puede contratarlas con terceros como regula el art. 12 de la Ley. Estos terceros tanto pueden ser empresas privadas autorizadas para la gestión de residuos, como municipios u otras entidades locales o Administraciones públicas que cuenten con instalaciones adecuadas, mediante la correspondiente contraprestación. Hay que advertir que estos contratos con las entidades locales no constituyen la forma de participación de las mismas en los sistemas integrados de gestión que se regula en los arts. 9 y 10.2 de la Ley de Envases; se trata de negociaciones al margen de las previsiones de la Ley, sin perjuicio de que en la formalización de los convenios de participación, a los que luego nos referiremos, se pueda contemplar este aspecto.

d) Identificar los envases mediante un símbolo acreditativo de cada sistema integrado de gestión, que se distinga del que se utilice para los envases gestionados por el sistema general de depósito. En la medida que ya hemos dicho que los sistemas integrados pueden organizarse a nivel estatal, pero tramitar autorizaciones en cada Comunidad Autónoma, el símbolo puede ser común, sin perjuicio de los añadidos identificativos, propios de cada nacionalidad o región, que la respectiva Administración autonómica tenga establecidos. El abono de la aportación al sistema, al que a continuación nos referimos, es el requisito que da derecho a los envasadores a utilizar el símbolo acreditativo del sistema al que pertenecen. 
e) Financiar el sistema integrado de gestión. Los gastos que origina el sistema han de ser costeados, lógicamente, por los envasadores y comerciantes miembros de cada sistema integrado mediante aportaciones económicas de cada uno a la entidad gestora del sistema. Ahora bien, la Ley no deja este punto a la libre articulación de cada sistema, sino que en el art. 10.1 contempla una única modalidad. De acuerdo con este precepto, los envasadores harán una aportación consistente en una cantidad por cada producto envasado puesto por primera vez en el mercado nacional. Esta cantidad, única para todo el ámbito territorial del sistema, se fija de forma variable en función de los diferentes tipos de envases y materiales, y ha de ser objeto de acuerdo entre la entidad gestora del sistema y los agentes económicos integrados en el mismo. Hay que entender que esta aportación por envase no deben hacerla sólo los envasadores, sino también los responsables de la primera puesta en el mercado nacional de los productos envasados, cuando aquellos no pueden ser identificados. Además y aunque ello ya no se establezca en la Ley, es lógico que los comerciantes integrados en el sistema también tendrán que hacer algún tipo de aportación económica para contribuir a sufragar los gastos de la organización. En su versión original, el segundo párrafo del art. 10.1 de la Ley, la cantidad por envase que aporta al sistema integrado cada uno de sus miembros «no tiene la consideración de precio, ni está sujeta a tributación alguna»; por consiguiente, este importe no estaba gravado por el Impuesto sobre el Valor Añadido. Pero en la

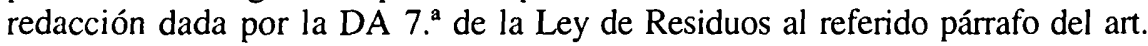
10.1 de la Ley de Envases, desaparece este inciso, de lo que se deriva que las aportaciones económicas que hagan las empresas a los sistemas integrados sí estará sujetas a IVA ${ }^{35}$.

f) Prestar una garantía, mediante fianza, aval bancario o cualquier otro medio que, en cuantía suficiente, pueda responder del cumplimiento de las obligaciones económicas del sistema, a juicio de la Administración autonómica autorizante.

g) Mantener un flujo de información permanente con la Administración autorizante, y someterse a los mecanismos de control y seguimiento que ésta imponga. De acuerdo con el art. 11 de la Ley, en los procedimientos y formas de control y seguimiento, las Comunidades Autonómas han de asegurar la participación de las Entidades Locales y de las organizaciones de usuarios.

35 La exención del apartado $6^{\circ}$ del art. 20 de la Ley de este Impuesto únicamente alcanza a los servicios prestados a miembros de uniones, entidades y agrupaciones, incluidas las de interés económico, siempre que estos miembros «ejerzan una actividad esencialmente exenta o no sujeta», lo que no es el caso de los envasadores y comerciantes socios del ente asociativo gestor del sistema integrado. Sobre la aplicación del IVA a la gestión de los envases, ver la Resolución de la Dirección General de Tributos de 30 de septiembre de 1998 (BOE $n .^{\circ} 257$, de 27 de octubre siguiente). 
h) Como en el sistema de depósito, quedan excluidos de los sistema integrados los envases industriales y los comerciales, los poseedores de los cuales vienen obligados por la Disposición Adicional Primera 1 de la Ley 11/1997 a entregarlos a empresas de reciclaje, en aplicación del art. 12 de la misma Ley; ello sin perjuicio de que, voluntariamente, los responsables de dichos envases decidan someterse al sistema de depósito o al de los sistemas integrados de gestión.

Se puede advertir pues que, en principio, los sistemas integrados regulados en los arts. 7, 8, 10.1,11 y 12 de la Ley se organiza y funcionan -a modo del sistema dual alemán - totalmente al margen del servicio municipal. Cuestión ésta decisiva para una correcta interpretación de la Ley de Envases, pero que suele pasar inadvertida. Se trataría pues de un modelo similar al sistema dual alemán. Las entidades locales se limitarían a autorizar la instalación de contenedores en la vía pública y a participar, junto a consumidores y usuarios, en el control y seguimiento de los sistemas integrados de gestión. En la modalidad de sistemas integrados de gestión, como en el sistema de depósito y devolución, el servicio, aunque de prestación privada, sigue siendo público, pero difícilmente puede decirse que se mantenga la titularidad municipal sobre el mismo. Más bien es la Comunidad Autónoma la que pasa a asumir dicha titularidad, en la medida que es su Administración la que regula, asegura y controla la efectiva realización por parte del sector privado de la misión de servicio público que la Ley les encomienda. Con respecto a los envases y residuos de envases, la Ley 11/1997 habría modificado parcialmente la reserva que, sobre el servicio de recogida, tratamiento y aprovechamiento de residuos y en favor de los entes locales hace, el art. 86.3 de la Ley básica del Régimen Local. La contrapartida para estas entidades es que - en teoría por lo menos- ya no son responsables, ni han de financiar, por tanto, la gestión de esta clase de residuos.

En cuanto a la titularidad patrimonial de los residuos de envases, lo que se ha dicho con respecto al sistema de depósito es igualmente válido para los sistemas integrados de gestión. Los municipios no adquieren en ningún momento la propiedad sobre dichos residuos salvo, claro está, aquellos envases y residuos de envase que son abandonados por los consumidores y que han de ser recogidos por los servicios municipales de residuos o de limpieza. Pero es en este punto donde la exención del sistema de depósito para aquellos agentes que se incorporen a los sistemas integrados, sin contrapartida alguna para las entidades locales no parece equitativa.

En el sistema de depósito, se supone que la cantidad que el consumidor deja como «prenda» de la devolución del envase usado o del residuo del mismo incentiva a su retorno y, por tanto, los residuos de envases tienden a desaparecer del sistema público de recogida. Pero en el sistema de gestión integrado, basado sobre todo en la recogida en «las proximidades del domicilio» de los consu- 
midores, únicamente la conciencia cívica y ambiental de éstos garantiza unos determinados resultados, más o menos satisfactorios, en orden a alcanzar los objetivos de la Ley. Y como es sabido este grado de concienciación ciudadana no se consigue sin una fuerte inversión en campañas de formación, información y publicidad en todos los medios; y ello sin olvidar la imprescindible colaboración y compromiso de entidades locales, organizaciones de usuarios, centros docentes, asociaciones de vecinos, grupos ecologistas, y demás entidades cívicas, empresariales y sindicales. Una acción y unos costes, en fin, que no aparecen contemplados en la Ley. Y, correlativamente, lo que la Ley tampoco prevé es la financiación de la gestión de los residuos de envases que los consumidores «no concienciados» continuarán abandonando junto con los demás residuos y de los que el servicio municipal deberá seguir haciéndose cargo. El principio de «quien contamina paga» no se hace pues plenamente efectivo, ni mucho menos, en los sistemas integrados de gestión.

\subsubsection{Los sistemas integrados de gestión con participación de las entidades locales}

Esta imprevisión es indicativa de que, así como la voluntad del legislador no está en que el sistema de depósito y devolución sea la modalidad realmente ordinaria de aplicación de la Ley de Envases, tampoco lo está en que los sistemas integrados de gestión, en su versión de sistemas duales e independientes del servicio municipal, sean la alternativa al sistema de depósito. Todo el articulado de la Ley conduce, inexorablemente, a que lo que en realidad se implante, como modalidad de desarrollo ordinario de esta norma, sean los sistemas de gestión integrados en su variante de participación voluntaria de las entidades locales. En realidad, pues, la excepción de la excepción al sistema general de depósito es lo que el legislador, subrepticiamente, plantea como auténtica alternativa y, en definitiva, como única fórmula de aplicación de la Ley.

Los sistemas integrados de gestión con participación de las entidades locales constituyen un modelo de gestión muy parecido al francés, aunque -como ya hemos advertido- aquel se distingue por la obligatoriedad de la participación de los municipios o de sus mancomunidades. En la fórmula de la Ley española, la participación de las entidades locales es voluntaria, y se formaliza mediante convenio entre cada ente local y la entidad gestora que actúa en el correspondiente ámbito territorial autonómico. Estos convenios forman parte del tipo de negocios con particulares excluidos de la Ley de Contratos de las Administraciones Públicas, en aplicación del apartado d) de su art. 3.1. Esta voluntariedad de la participación local se desprende directamente, en primer lugar del propio régimen de convenio del que dicha participación depende, pero también se deduce de la relación de determinaciones que, según el art. 8.1 de la Ley, han de contener las solicitudes de autorización de los sistemas inte- 
grados, entre las cuales no hay alusión alguna a ningún convenio o proyecto de convenio con las entidades locales. Por otra parte, el necesario acuerdo de voluntades, entre el sistema integrado y la entidad local, implicaría que lo normal fuese que un sistema integrado actúa de forma no homogénea; a veces en colaboración con una los municipios de su ámbito territorial -ya sea individualmente o por medio de entes locales supramunicipales-, y en otros municipios de forma independiente o «dual» con respecto al servicio municipal.

De todas formas, ese carácter «voluntario» de la participación local es pura falacia en el caso de Ayuntamientos y otras entidades locales que ya tengan implantado un sistema de recogida selectiva de residuos de envases. En estos supuestos, la necesidad de financiar un servicio, que se costea con tasas y que acostumbra a ser deficitario, forzará el acuerdo de participación en los sistemas integrados.

La referencia genérica a las entidades locales es relevante, puesto que la participación en los sistemas integrados tanto la pueden formalizar Ayuntamientos o Mancomunidades, o bien corporaciones locales de creación legal, como Áreas metropolitanas, Comarcas o Diputaciones provinciales; recuérdese que la reserva del servicio de gestión de residuos se hace en el art. 86.3 de la Ley básica de Régimen Local en favor de los entes locales en general. Por consiguiente, la imposibilidad de un municipio de participar individualmente en un sistema integrado de gestión de residuos de envases debería ser normalmente suplida por la participación de la correspondiente entidad supramunicipal, siendo las Diputaciones las que, en todo caso, podría participar sustituyendo a los municipios de la Provincia que no lo puedan hacer, ni individualmente ni asociados en mancomunidades. Por el momento y salvo los casos en los que la gestión de residuos esté atribuida por ley ${ }^{36} \mathrm{o}$ asumida conforme a ella, esta participación supramunicipal no puede hacerse a título de subrogación, puesto que se trata de una actuación voluntaria y, además y por ello, no estamos ante un servicio mínimo y obligatorio para toda clase de municipios, de los que contempla el art. 26.1 b) ${ }^{37}$. La Ley de Envases tampoco contempla la subroga-

36 Como son los casos del «Consell Metropolità de l'Horta» en Valencia, o de la «Entitat Metropolitana de Serveis Hidràulics i Tractament de Residus» en Barcelona. Al respecto, M. C. BARRERO, Las áreas metropolitanas, Madrid, 1993; J. PERDIGó, «Organización administrativa del medio ambiente en los grandes municipios y áreas de conurbación», en Derecho del Medio Ambiente y Administración Local, op. cit., págs. 371 a 394. En el sentido apuntado, en el Convenio marco entre la Junta de Residuos de la Generalidad de Cataluña y ECOEMBES, suscrito el 25 de mayo de 1998, se establece que en el ámbito de la conurbación de Barcelona la adhesión al Convenio marco y, por tanto, la participación en el sistema integrado corresponde a la referida Entidad Metropolitana y no a los municipios.

37 Esta situación no ha cambiado con la Ley de Residuos. Como ya hemos dicho, el art. 20.3 de la Ley 10/1998 declara servicio obligatorio la recogida selectiva de los residuos urbanos susceptibles de valorización en los municipios de más de 5.000 habitantes pero, por lo que a la recogida selectiva de envases se refiere, remite a la Ley de Envases. 
ción de la Administración de la Comunidad Autónoma, como ente público que participe en los sistemas de gestión, en lugar de los municipios. Ello sin perjuicio, claro está, de la posible participación en los sistemas integrados de las Comunidades uniprovinciales y de la foral de Navarra, que pueden ejercer competencias locales en virtud de lo dispuesto en su respectivo ordenamiento y en el art. 40 de la Ley Básica de Régimen Local, únicos supuestos a los que se puede referir el tercer párrafo del art. 10.2 de la Ley cuando alude a que las Comunidades Autónomas que realicen las operaciones de separación, clasificación y transporte a las que se refiere el art. 9.1 de la misma Ley también deberán ser compensadas económicamente por los sistemas integrados.

En relación con lo anterior, el contenido del art. 9.2 de la Ley de Envases es harto confuso. Se establece en este precepto que las entidades locales que no participen en un sistema integrado de gestión convendrán con la Comunidad Autónoma un procedimiento que permita el cumplimiento de los objetivos de la Ley en su ámbito territorial. Aquí el legislador no tiene en cuenta que, de no participar un determinado municipio, ubicado en el ámbito territorial que abarca el sistema integrado, el ente gestor del mismo se ha de hacer cargo directamente de la recogida selectiva en ese término municipal. Aunque nada impide que, incluso con carácter general y para los pequeños municipios, se precise en la solicitud de autorización del sistema integrado que la no prestación del servicio de recogida selectiva en esos municipios no compromete el cumplimiento de los objetivos de reciclaje y valorización. En cambio, a lo que parece querer referirse el precepto indicado es a que la no participación de un municipio en el sistema integrado de su ámbito implica que es el propio Ayuntamiento el que se hace responsable, tanto del servicio como del alcance de los objetivos, supuesto manifiestamente incoherente y contrario al modelo de gestión de envases que la Ley contempla.

En virtud del convenio, dice el segundo párrafo del art. 9.1 de la Ley, las entidades locales «se comprometerán» - expresión que confirma esa voluntariedad relativa - a realizar la recogida selectiva de los residuos de envases, incluidos en el sistema integrado de que se trate, y a su transporte hasta los centros de separación y clasificación o, en su caso, directamente a los de reciclado y clasificación. En estos centros, la entidad gestora del sistema integrado, directamente, o bien la empresa autorizada para la gestión de residuos con la que haya contratado el sistema integrado (arts. 8.1 párrafo tercero y 12 párrafo primero) han de hacerse cargo de los residuos de envases para su reciclado o valorización.

La distinción que se hace entre uno u otro tipo de centros puede tener diferentes significados. El transporte local se hará en general a los centros de separación, selección o clasificación ${ }^{38}$. Pero puede hacerse directamente a los

38 La Ley no prejuzga el modelo de recogida; recogida selectiva de los distintos tipos de envases en di- 
establecimientos de reciclado, cuando la recogida selectiva en origen garantice un alto grado de fiabilidad en la selección del material, como es el caso de los envases de vidrio o de cartón. Los residuos de envases de metal, plástico y brics, recogidos en un mismo contenedor requerirá siempre un proceso de separación, selección y clasificación. Ahora bien, puede darse el caso que, si la entidad dispone de establecimientos adecuados, se convenga que el referido proceso de selección se realizará en las dichas plantas. En este supuesto, la entidad local, o bien asume un segundo transporte hacia los distintos centros de reciclado y valorización, o el ente gestor del sistema integrado se hace cargo del mismo. Por supuesto que, en uno y otro caso, la compensación económica que ha de percibir la entidad local no es la misma.

También puede darse un tercer supuesto, consistente en que la entidad local asuma las operaciones el reciclaje u otras formas de valorización. En cuanto al reciclaje ello será quizás poco habitual ${ }^{39}$. Otra cosa van a ser los casos de entidades locales que dispongan de instalaciones de incineración de residuos municipales con generación de energía. Este supuesto plantea una cuestión de gran interés. Por una parte, en las operaciones de separación, selección y clasificación se genera una determinada cantidad de materiales rechazados - bien porque son envases no reciclables, bien porque son otra clase de residuos que han sido arrojados a un contenedor inadecuado - tanto unos como otros pueden ser incinerados en instalaciones de la entidad local, por lo que el convenio ha de contemplar este extremo, tanto funcional como económicamente. Pero teniendo en cuenta las pocas plantas de incineración que hay en España, lo normal será que la fracción marginal rechazada en la operación de selección de los residuos de envases tenga que ser objeto de disposición final en vertedero. Y aún hay más, en la recogida ordinaria no selectiva habrá, inevitablemente, una cantidad importante de residuos de envases que los consumidores no habrán depositado en los correspondientes contenedores de recogida selectiva y que también deben ser objeto de tratamiento, ya en instalaciones de incineración o en vertederos controlados. Como veremos más adelante, al tratar de los aspectos económicos de la participación de los entes locales en los sistemas integrados, la entidad gestora de éstos también deberá hacerse cargo del tratamiento de todos estos residuos procedentes, o no, de la recogida selectiva.

\footnotetext{
ferentes contenedores según la materia, o bien el sistema húmedo/seco con un contenedor para la fracción orgánica y otro para los demás envases, aunque con recogida selectiva de papel y vidrio. El modelo de recogida será por tanto una de los principales cuestiones del convenio.

39 Un ejemplo sería la planta que la Entidad Metropolitana de Servicios Hidráulicos y Tratamiento de Residuos tiene entre los municipios de Gavá y Viladecans, en la que, además de los procesos de separación y clasificación, se produce granza de plástico que se comercializa a los fabricantes de envases y otros productos pásticos.
} 
LOS ENVASES Y EL SERVICIO MUNICIPAL, DE RECOGDA ...

\subsubsection{Financiación de la participación de las entidades locales en los sistemas integrados}

El mismo régimen de financiación del sistema integrado que actúa de forma independiente o «dual», regulado en el art. 10.1 de la Ley, es de aplicación a los sistemas integrados con participación de la Administración local. La diferencia está en que, en el primer supuesto, la Ley no regula, lógicamente, las relaciones contractuales que el ente gestor del sistema pueda establecer con terceros; mientras que, cuando el «tercero» es el municipio o entidad local estas relaciones, en particular, en su aspecto económico, sí que son objeto de regulación.

La base de este régimen económico consiste en que el ente gestor del sistema integrado ha de abonar a la entidad local con la que colabora y en los términos que se establezcan en el convenio la «diferencia de coste entre el sistema ordinario de recogida y transporte y tratamiento de residuos y desechos sólidos urbanos en vertedero controlado y el sistema de gestión integrado», regulado en la Ley.

Para fijar el factor de partida cuyo coste debe restarse del coste de la nueva modalidad de servicio, con el fin de obtener el coste diferencial, únicamente debe considerarse el coste de la recogida tradicional, del transporte y del depósito en vertedero de los residuos de envases, no del conjunto de los residuos sólidos urbanos, puesto que entonces el diferencial sería ruinoso para las entidades locales. A su vez, en los costes del nuevo sistema - factor del que hay que restar el anterior- no se incluyen sólo los gastos de explotación y mantenimiento, sino también el importe de la amortización y de la carga financiera de las inversiones, tanto en material móvil como en infraestructuras. Como aclara el Reglamento de la Ley, en el coste de las inversiones se puede entender comprendido también el de las ya realizadas con anterioridad a la firma del convenio entre la entidad local y el sistema integrado, en la parte proporcional al tiempo de uso que reste. Como ya hemos visto en el epígrafe anterior, el volumen de este gasto de la entidad local dependerá de si ésta sólo asume las operaciones mínimas previstas por la Ley - recogida selectiva y transporte hasta los centros de selección-o, además, se hace cargo de la selección y de otras operaciones de tratamiento. Y como ya hemos adelantado también, en el coste del nuevo sistema hay que incluir los residuos de envases que son abandonados en el sistema ordinario de recogida municipal y que son valorizados mediante incineración de energía en instalaciones de la entidad local, restando claro está los ingresos que dicho ente pueda obtener por la venta de la energía generada. 
Teniendo en cuenta que mientras el sistema de depósito eliminaría del objeto del servicio local los residuos de envases, desapareciendo así los costes de su recogida y tratamiento, no parece justo que la simple voluntad de los agentes económicos de acogerse a la excepción de los sistemas integrados de gestión, obligue a las entidades locales a seguir asumiendo el gasto teórico de la recogida y disposición en vertedero de los residuos de envases que se recojan selectivamente. Y más injusto es que, además, las entidades locales tengan que seguir costeando la recogida y el tratamiento tradicionales de los residuos de envases que los usuarios no entreguen o no depositen selectivamente. Partiendo de esta base, en realidad el coste diferencial debería coincidir con el coste íntegro de la inversión y la explotación de la recogida selectiva y el transporte, puesto que las entidades locales ya se hacen cargo — sin compensación alguna por parte del sistema integrado- de la recogida ordinaria y del tratamiento en vertedero de los residuos de envases que, por desidia de los consumidores, no van a parar al sistema de recogida selectiva.

Pero es que, además, los nuevos costes que para las entidades locales implica su participación en los sistemas integrados no se limitan al «diferencial». En primer lugar, debe tenerse en cuenta que la inversión a realizar por las entidades locales no es sólo la que tiene por objeto la recogida selectiva de los envases, sino que para implantar este sistema, han de modificar íntegramente el modelo de recogida tradicional. Esto implica que la inversión de recogida segregada de la fracción orgánica (residuos vegetales, de carne y de pescado), y de las demás fracciones que no son residuos de envases recogidos selectivamente, también debería ser financiada por el sistema integrado, puesto que es inherente al establecimiento del nuevo sistema de recogida exigido por la Ley de Envases. En el bien entendido que estaríamos hablando de los costes de inversión en los elementos de la recogida (contenedores y vehículos de transporte), no de la inversión en infraestructuras de tratamiento de la fracción orgánica ni de la fracción de rechazo, y por supuesto y en ningún caso de los costes de explotación.

Pero es que en la medida que el progreso de la recogida selectiva no depende sólo, ni principalmente, de la buena gestión de la entidad local sino, sobre todo, del nivel de conciencia cívica y ambiental de los usuarios hay que añadir otro concepto adicional de coste, constituido por los gastos de las campañas de publicidad, formación e información que, en un sistema integrado con participación de la entidad local, han de ser gestionadas por ésta, sin perjuicio de la necesaria colaboración con el ente gestor del sistema. Hay que entender que de la eficacia de dichas campañas dependerá la disminución del otro factor de coste adicional. 
La incorporación de todos estos otros conceptos —así como el referido a los costes de inversión de la recogida segregada de las fracciones orgánica y de rechazo — tiene fundamento - además de en una interpretación sistemática de la Ley de Envases- en el propio párrafo segundo del art. 10.2 de la misma, en el que se estipula que los sistemas integrados deben compensar a las entidades locales «por los costes adicionales que, en cada caso, tengan efectivamente que soportan. En definitiva, que coste diferencial y costes adicionales no son una misma cosa, a pesar de la confusión que introduce al respecto el art. 10.2 del Reglamento, en relación con el 10.2 de la Ley, al identificar coste adicional con coste diferencial ${ }^{40}$.

\subsubsection{Naturaleza de la financiación de los sistemas integrados a los entes locales que participan en su gestión y su eventual sujeción al IVA}

Ya hemos visto que las aportaciones económicas que realizan los envasadores, comerciantes y demás agentes económicos miembros de los sistemas integrados no tienen la consideración de precio, ni están sujetas a tributación alguna. Pues bien nada parecido se dice, en el art. 10.2 de la Ley, acerca de las aportaciones que los sistemas integrados han de realizar a las entidades locales que, de acuerdo con el convenio de colaboración que han suscrito, participan en la gestión del mismo. Esta omisión del legislador implica que está en cuestión: a) el carácter de contraprestación que estas aportaciones puedan tener, b) la naturaleza de la misma, y c) si está sometida o no a tributación y en particular al IVA.

En el segundo párrafo del precepto citado se habla de «compensar a las entidades locales», y en el Reglamento se acuña la expresión de «compensación» para referirse a estas aportaciones. Parece haber pues la velada intención del legislador - y del Gobierno- de obviar la calificación de contraprestación o

40 Este planteamiento ha sido, en parte, recogido en el Convenio marco entre la Junta de Residuos de la Generalidad de Cataluña con ECOEMBES, al que pueden adherirse los entes locales. En este Convenio, las expresiones de coste «diferencial» 0 «adicional» son meramente nominales ya que, de hecho se refieren a costes efectivos. Así, junto a un coste «adicional» de recogida selectiva, aparecen otros costes como recogida domiciliaria o puerta a puerta, deixalleries o centros de aportación de determinados residuos, separación y clasificación, valorización energética, información ciudadana y campañas de promoción. Otra cosa es el debate acerca de la fijación de estos precios. En el Convenio, el precio medio del coste diferencial de la recogida selectiva se sitúa en 33 ptas./kg.; ahora bien, según el tipo de comarca -urbana, semiurbana o rural- este precio puede ser de 27,6, 29,9 641,4 ptas., respectivamente, a los que se añaden 3,1 ptas. $/ \mathrm{kg}$. en concepto de amortización y reposición de contenedores. Estos importes son discutidos por la Entidad Metropolitana - comarca urbana- que calcula el coste de la recogida selectiva 33,8 ptas./kg., más 4,5 por amortización y reposición de contenedores.. De todas formas, parece que en la Comunidad de Madrid se manejan cifras muy inferiores, $22,4 \mathrm{ptas} . / \mathrm{kg} .$, con el correspondiente descontento de los representantes municipales (El Pais, 7 de abril de 1998). 
precio. Sin embargo, no parece posible para el buen funcionamiento económico y contable de los sistemas y, en particular, de sus entes gestores, que las aportaciones tengan un régimen impreciso de compensación, ayuda o subvención. Además, si una parte sustancial de estas aportaciones se habrá de hacer en base un precio unitario por envase o residuo de envase, selectivamente recogido, transportado y entregado en unas determinadas condiciones de clasificación, no parece posible obviar el carácter económico de contraprestación por un servicio prestado por la entidad local al ente gestor del sistema. La cuestiones relevantes serán, pues, la naturaleza jurídica de esta contraprestación y su sujeción al IVA.

La actividad prestacional de la entidad local que participa en el sistema integrado no deja de formar parte de su servicio público de recogida, transporte $\mathrm{y}$, en su caso, tratamiento de residuos municipales. Ahora bien, el servicio prestado al sistema integrado por el municipio u otro ente local es un supuesto de prestación particularizada de un servicio público que podría, en principio ser objeto de una exacción específica distinta de la tasa por recogida y tratamiento establecida con carácter general. Con respecto a la posible califcación de tasa o precio público, parece que en el caso que nos ocupa estaríamos ante una manifestación de la segunda categoría, puesto que, incluso conforme a los criterios más rigurosos de voluntariedad y monopolio de hecho, establecidos por la Sentencia del Tribunal Constitucional 185/1995, y recogidos por la Ley $25 / 1998$, el sistema integrado es perfectamente libre para gestionar los residuos de envases sin participación de las entidades locales, como al mismo tiempo estas entidades también tiene la libertad de participar o no en la gestión del sistema.

Sin embargo, parece bastante evidente la voluntad del legislador de rehuir, por lo menos, la consideración tributaria de tasa que, por otra parte, tampoco encajaría con los requisitos de la Sentencia del Constitucional antes aludida. A partir de ahí y aunque tampoco se califique la contraprestación en cuestión de «precio público», como institución legal regulada en la Ley de Haciendas Locales y en la Ley de Tasas y Precios Públicos, es inevitable encuadrarla entre los ingresos de Derecho público de las entidades locales, más o menos atípicos, como pueden ser el canon que el concesionario de un servicio público abona en favor de la Administración concedente, o las cuotas de urbanización que los propietarios de las fincas aportan al Ayuntamiento en la ejecución de polígonos o unidades de actuación por el sistema de compensación, contempladas en el Reglamento de Gestión Urbanística. Y tratándose de ingresos de Derecho público, aportados por particulares a título de contrapestación, si no en las concretas categorías de tributo ni de precio público, sí que deben encuadrarse en la categoría más amplia —en parte rescatado por la citada Sentencia 185/95 del Tribunal Constitucional- de «prestaciones de patrimo- 
niales de carácter público», que muy genéricamente contempla el art. 31.3 de la Constitución española ${ }^{41}$.

El carácter de contraprestación por la prestación de un servicio y su naturaleza no tributaria ponen de entrada muy difícil la no sujeción a la exención del IVA, por lo menos tal y como se transpuso al Derecho español la sexta Directiva comunitaria al respecto. El art. 4.5 de esta Directiva no exige que las contraprestaciones no sujetas sean necesariamente «tributarias», sino que las operaciones que se realicen lo sean en ejercicio de funciones públicas, y así lo confirmó el Tribunal de Justicia de las Comunidades en Sentencias de 17 de octubre de 1989 y de 15 de mayo de $1990^{42}$. Y aunque se trate de una utilización voluntaria y establecida mediante convenio, es claro que, en la recogida selectiva de los residuos de envases, los sistemas integrados se sirven de un servicio público local cuya contraprestación, tanto si se tratara de un supuesto ordinario de precio público, como del supuesto más atípico que nos ocupa, podría no quedar sujeto a IVA en aplicación estricta del ordenamiento comunitario. Pero con la vigente legislación española, parece inevitable la sujeción a IVA de las aportaciones o compensaciones a las que se refiere el art. 10.2 de la Ley de Envases, si bien es ésta una cuestión que debemos dejar abierta para que los especialistas se pronuncien al respecto.

\subsubsection{Titularidad sobre los residuos de envases en los sistemas integrados con participación de la entidad local}

Ya hemos establecido que en el sistema de depósito y devolución y en los sistemas integrados de gestión sin participación municipal, los residuos de envases que efectivamente entran en circuito de retorno o que son recogidos selectivamente no pasan a ser bienes patrimoniales del municipio u otra entidad local titular del servicio de gestión de residuos. Cuando los sistemas integrados se gestionan con la participación de la entidad local es claro que ésta, a partir del momento de la recogida selectiva hasta la entrega de los residuos de envases, es «poseedora» de dichos residuos. Ahora bien, ¿esta posesión implica también propiedad sobre los residuos de envases recogidos. Y, lo que es más importante, supuesta la propiedad sobre los residuos de envases?, ¿la entrega al

\footnotetext{
41 J. PERDIGo, «Les tarifes dels serveis locals», en Dret Local. Ordenances, activitats $i$ serveis públics, coord. T. Font Llovet, EUB-Marcial Pons-PUAB, Barcelona, 1997, págs. 559 a 596.

42 Sin embargo, la doctrina sobre esta cuestión tiene bastantes matices. Así, X. CORS MEYA en «Precios públicos, parafiscalidad, sujeción al IVA y exacciones de efectos equivalentes a derechos de aduanas», $R E D F, \mathrm{n}$. 67, 1990; P. M. HERRERA MOLINA, en «El IVA en los precios públicos desde la perspectiva comunitaria», Impuestos, os $^{\text {os }}$ 15-16, 1990; y R. FALCÓN TELLA, en «Los entes públicos como sujetos pasivos del IVA», Impuestos $I, 1992$.
} 
sistema integrado o a los recicladores que su ente gestor haya dispuesto ha de hacerse mediante precio? En definitiva, además de la financiación del coste diferencial y de los costes adicionales por parte del sistema integrado, ¿la entidad local puede obtener ingresos por la venta de los residuos de envases que sería de su propiedad?

De acuerdo con el Reglamento de la Ley de Envases, podría entenderse que sí se produce esta apropiación, puesto que en el apartado b) de su art. 10.2 se dice que el coste adicional que tengan que soportar «es independiente del posible valor económico de los residuos y de su régimen de propiedad, que se regularán por las nonnas generales establecidas en la legislación sobre residuos». Pero, a pesar de ello y a nuestro entender, las respuestas a las preguntas que nos hemos formulado han de ser rotudamente negativas. De la interpretación sistemática de la Ley hay que deducir que, si en el sistema de depósito y en los sistemas integrados sin participación local, la entidad local nunca accede a la propiedad de los envases o residuos de envases, salvo que escapen a dichos sistemas y sean abandonados y recogidos por el servicio municipal, cuando el sistema integrado se gestiona con la participación de la entidad local, ésta tampoco puede llegar a ser propietaria de los residuos de envases, por la sencilla razón que la entidad local está prestando al sistema integrado un servicio de recogida, transporte y, en su caso, tratamiento del que dicho sistema, o su ente gestor, es el único responsable. Ello puede ser así en el modelo francés, pero no en el de la vigente Ley española de Envases. La remisión que el Reglamento hace al régimen de propiedad que se pueda deducir de la vigente legislación general de residuos urbanos - art. 20.1 de la Ley $10 / 98$ - resulta totalmente vacía de contenido, puesto que es la propia Ley de Envases la que modifica dicho régimen de propiedad, en el sentido de que los residuos de envases son entregados por sus poseedores al ente gestor del sistema integrado, ya sea directamente o bien por medio de los entes locales, cuando éstos participan en el sistema.

Por otra parte, la posible intención de que, con la disposición aludida, el Reglamento de la Ley de Envases pretenda conseguir unos ingresos suplementarios para las entidades locales, e incentivar así su participación en los sistemas integrados, es infructuosa por dos razones. La primera, porque el valor económico de los residuos de envases, prácticamente, coincide con el del coste de su recogida selectiva y su transporte. La prueba es que, en el sistema tradicional de recogida y depósito en vertedero controlado, su valor no sólo es nulo, sino que es incluso un valor negativo, puesto que únicamente genera gastos y nunca ingresos. Siendo así, pretender la entrega mediante precio de los residuos de envases, después de que el sistema integrado se haya hecho cargo del coste diferencial y, en particular, de todos los costes adicionales a los que nos hemos referido, sería tanto como pagar dos veces por una misma cosa o servicio. Y en segundo lugar porque, aun cuando así fuere, es decir, que se conside- 
rara que la entidad local que participa en el sistema se apropia de los residuos de envases recogidos selectivamente, de forma que la entrega al sistema integrado se produce previo pago de un precio independiente de los costes que asume el sistema, es obvio que entonces los ingresos obtenidos por la entidad local por la venta de los residuos de envases deberían restarse de los costes de explotación, con lo que el resultado nunca sería más beneficioso para la entidad local. Esto es lo que viene a decir —creemos - el segundo párrafo del art. 10.2 b) del Reglamento de la Ley de Envases.

Desde una perspectiva municipalista, más vale insistir en una interpretación amplia de los costes adicionales, a los que se refiere el segundo párrafo del art. 10.2 de la Ley, entendiéndolos como unos costes distintos y que deben añadirse al coste diferencial del primer párrafo de este artículo, que no buscar ingresos suplementarios en una supuesta propiedad municipal sobre los envases y residuos de envases.

Cuestión completamente distinta es que las Entidades locales que participen en los sistemas integrados sí que harán de su propiedad aquellas fracciones residuales recogidas selectivamente, pero que no son residuos de envases. Estas fracciones pueden ser relativamente importantes en la recogida selectiva de papel, en la que se mezclan envases de cartón con periódicos, revistas y otras publicaciones, papel de oficina, etc. Menos relevante será la magnitud de cristales rotos que, por ejemplo, se recojan junto con los residuos de envases de vidrio; y mucho menos la de materiales de plástico, metal o madera que, no tratándose de envases, se recojan en los mismos contenedores. En todos estos supuestos sí que, previo acuerdo con el sistema integrado, las entidades locales podrán venderle estos residuos de su propiedad, sin que los ingresos correspondientes tengan que restarse de los costes de explotación de la recogida selectiva.

En realidad, la alternativa realmente de alcance a la cuestión planteada sería la antes apuntada consideración de los residuos municipales, incluidos los residuos de envases, como bienes de dominio público de los que todos, entidades locales, envasadores y comerciantes -en cualquiera de los sistemas en se organizaran- sería meros gestores. La naturaleza de dominio público de dichos residuos no impediría obtener un beneficio privado de su aprovechamiento y valorización, como igualmente ocurre con otros recursos demanializados como los mineros o los hídricos en régimen de concesión. Retomando lo propugnado con anterioridad: $1 .^{\circ}$ la consideración de los envases y residuos de envases como una forma de riqueza del país, subordinada por tanto al interés general, y $2 .^{\circ}$ la necesidad de velar por la utilización racional de estos recursos y, en particular, de aquellos otros recursos primarios con los que son manufacturados los envases, en orden a un desarrollo y un crecimiento "armonioso, equilibrado, sostenible y no inflacionista, y respetuoso con el medio", son razones que legi- 
timarían al legislador para declarar los residuos de envases bienes de dominio público, no tanto como una forma de apropiación pública sobre los mismos, como sobre todo un determinado régimen jurídico, que impone obligaciones de gestión de estos recursos, tanto a las Administraciones públicas como a los particulares.

\subsection{La intervención de las Comunidades Autónomas en la participación de las entidades locales en los sistemas integrados de gestión}

Pero el régimen de participación de las entidades locales en los sistemas integrados de gestión, que hemos descrito, resulta que tampoco es el que finalmente se pretende implantar con la Ley española de Envases. De nuevo por la vía de la excepción que tiende, sin embargo, a su generalización, el art. $9.3 \mathrm{de}$ la Ley establece que la participación no se hará mediante convenio entre cada entidad local y el sistema integrado sino que, en aquellas Comunidades Autónomas que «tengan aprobados planes de gestión de residuos sólidos urbanos», la participación local se llevará a cabo a través de la Administración autonómica.

La Ley no dice nada más respecto de este función de intermediación entre las Comunidades Autónomas, los sistemas integrados y las entidades locales. $\mathrm{Ni}$ se califica la naturaleza jurídica de esta intervención, ni se determina su grado. Sin embargo, las dos salvedades previstas en el sentido de que la intermediación autonómica no pueden privar, en última instancia, a cada entidad local a adoptar la decisión de participar, o no, en los sistemas integrados, y en todo caso ha de garantizar el coste diferencial y los costes adicionales de su participación, ya son bastantes indicativas. De lo que se trata es de que sean las Comunidades Autonómas las que pacten condiciones y formalicen convenios con los sistemas integrados, y de que las entidades locales acuerden o no su adhesión a dichos convenios. El Reglamento de la Ley así lo consagra finalmente. A pesar de esta predeterminación vale la pena hacer algún esfuerzo para caracterizar jurídicamente esta intervención autonómica en una competencia y en una actividad que - recordémoslo- constituye un servicio esencial reservado a las entidades locales.

Partiendo de ese presupuesto competencial, estaríamos ante un ejemplo de coordinación administrativa, de carácter imperativo u obligatorio, de la Comunidad Autónoma respecto de las entidades locales de su ámbito territorial, que prevén y regulan los arts. 10.2 y 59 de la Ley Básica de Régimen Local. En la gestión de residuos en general y la de los envases en particular se cumplen las tres condiciones que para esta coordinación fija el primero de los citados preceptos: que el servicio trascienda el interés propio de la entidad local, que incida de forma relevante en el interés más general de la Comunidad, y que se trate 
de competencias concurrentes o complementarias. Y, a más abundamiento, se da el requisito que añade el art. 59.1 de que el fin perseguido no se pueda conseguir por la vía de la cooperación voluntaria ${ }^{43}$. Ciertamente que en el supuesto que nos ocupa siempre les queda a las entidades locales la última palabra, a la hora de tomar la decisión de adherirse; pero ello es así por el propio modelo de gestión establecido por la Ley, en el que la no participación de una entidad local obliga al sistema integrado a actuar de forma independiente o dual en ese ámbito territorial. Además de esta libertad específica, con carácter general los arts. 10.2 y 59.2 de la Ley Básica de Régimen Local garantizan el ejercicio de las potestades de planificación, programación —en el marco claro está del programa autonómico- y sobre todo de ordenación y organización del servicio.

Pero la coordinación obligatoria tiene también unos presupuestos muy claros. En primer lugar su autorización por ley formal, que quedaría cumplimentada por la Ley 11/1997. A partir de esa autorización el Gobierno autonómico ha de desarrollar planes sectoriales; es decir, el plan de gestión de residuos sólidos urbanos que habilita a la Comunidad Autónoma para intervenir. Sin embargo, ello no parece suficiente ya que en estos planes, o en su desarrollo, se debe incluir el programa autonómico de gestión de residuos de envases y envases usados al que se refiere el art. 17 de la Ley de Envases, y que de contemplar la determinación de intereses generales, la fijación de objetivos y la determinación de prioridades que exige el art. 59.2 de la Ley básica de Régimen Local. Y por exigencia de una u otra Ley, o de ambas, en la elaboración de estos planes y programas han de participar las entidades locales, así como las organizaciones de consumidores y usuarios. Esta participación es de extraordinaria importancia puesto que será el medio para que la adhesión de las entidades locales sea realmente voluntaria e interesada y no forzada, o para evitar que permanezcan al margen de los sistemas integrados.

No parece que se deba insistir en la trascendencia que en este necesario acuerdo tienen los aspectos económicos. Pero además de un consenso acerca del importe del coste diferencial y de los costes adicionales, también es de gran interés la forma de pago de estas cantidades a las entidades locales. Aunque nada impide que dicho pago se efectúe directamente a las entidades locales por parte del ente gestor del sistema integrado, no parece que sea ésta la intención de las Comunidades Autónomas. Es por ello que, en previsión de que la intermediación autonómica alcanzara también el sistema de pagos, el Reglamento dispone que, una vez recibidos los fondos del sistema integrado, la Administra-

43 Sobre coordinación interadministrativa ver de L. PAREJO ALFONSO, Estado social y Administración Pública, Civitas, Madrid, 1983, págs. 129 a 138; de L. ORTEGA ÁlvarEz el ya citado El régimen constitucional de las competencias locales, INAP, Madrid, 1988, págs. 106 a 110. 
ción autonómica no puede demorarse más de un mes en hacer la correspondiente transferencia a cada entidad local, con el correspondiente interés legal en caso de incumplimiento. El que la intermediación autonómica alcance también el régimen de transferencias económicas añade mayor complejidad, si cabe, tanto a la calificación jurídica de las aportaciones del sistema integrado como, sobre todo, al régimen de comprobantes, facturas y cuotas de IVA a los que ya hemos hecho referencia; $y$, en la práctica éste puede ser uno de los problemas de más ardua solución.

La intervención de las Comunidades Autónomas, tal y como está prevista en la Ley de Envases, no contempla en ningún caso, la participación de la propia Administración autonómica en los sistemas integrados, ni siquiera en lugar de las entidades locales. Sólo las entidades locales supramunicipales, debidamente habilitadas para ello, pueden asumir esta participación. Y de no haber ninguna entidad local dispuesta a adherirse al convenio entre la Comunidad Autónoma y el sistema integrado, en ese ámbito territorial ha de actuar directamente el ente gestor del sistema. Como ya hemos dicho, la alusión a esta participación de la Administración autonómica que se hace en el tercer párrafo del art. 10.2 de la Ley, únicamente puede referirse a las Comunidades uniprovinciales. Para que una Comunidad Autónoma pudiera subrogarse en la participación de las entidades locales en los sistemas integrados de gestión de envases y residuos de envases sería preciso que ello se estableciera en una ley autonómica.

Finalmente, hay que recordar que el art. 59.2 de la Ley Básica de Régimen Local exige que se arbitren formas de control de la coordinación por parte de la Asamblea legislativa de la Comunidad Autónoma.

\subsection{Planificación y programación}

El art. 17 de la Ley 11/1997 contempla un modelo de planificación que culmina con un Programa Nacional de Gestión de Residuos de Gestión de Residuos Sólidos Urbanos. En este Programa Nacional se integra el Programa Nacional de Residuos de Envases y Envases Usados que ha de aprobar el Gobierno antes del 27 de abril de 1998. Siguiendo la pauta marcada por el art. 131.2 de la Constitución, el Ministerio de Medio Ambiente ha de redactar el Programa Nacional a partir de los Programas de cada Comunidad Autónoma ${ }^{44}$. Habida cuenta de que, tanto algunas Administraciones autonómicas y Entidades locales ya han aprobado Programas de Residuos y, en particular, de Residuos Urbanos, el segundo párrafo del art. 17 exige que se revisen para incorporar en ellos determi-

44 Sobre planificación económica, S. MARTin-RETORTLLO, Derecho Administrativo Económico I, La Ley, Madrid, 1988, págs. 326431. 
naciones específicas sobre gestión de envases y, por supuesto, que los que se redacten de nuevo también contemplen este extremo. Y hay que insistir en la relevancia que, a nuestro entender, tienen los programas autonómicos de gestión de envases y residuos de envases, en la medida que de su aprobación depende que las Comunidades Autónomas puedan hacer efectiva la intermediación entre los sistemas integrados y las entidades locales, prevista en el art. 9.3 de la Ley. Asimismo, es imprescindible que estos planes o programas autonómicos tengan el carácter de planes sectoriales susceptibles de constituirse en los instrumentos de la coordinación imperativa sobre los entes locales a la que se refiere el art. 59 de la Ley Básica de Régimen Local ${ }^{45}$.

En particular, para el seguimiento del desarrollo de ese Programa Nacional de Residuos de Envases y Envases Usados, y del cumplimiento de los objetivos de la Ley se prevé la participación de las Entidades locales y de las organizaciones de consumidores y usuarios además, claro está, de la Administración General del Estado y de las Administraciones de las Comunidades Autónomas. Estos planes empresariales deberán ordenarse al cumplimiento de las determinaciones del Programa Nacional y de los Progamas Autonómicos.

La planificación y la programación en materia de gestión de envases no se limita a los instrumentos autonómicos y estatales. El segundo párrafo del art. 17 de la Ley alude también a los planes locales; y recordemos al respecto que la coordinación de las entidades locales a través de planes sectoriales del citado art. 59 de la Ley Básica de Régimen Local, ha de preservar las potestades de planificación, programación y ordenación de los entes locales sujetos a coordinación. Ello es corroborado por el art. 5.5 de la Ley de Residuos que reconoce esta potestad de las entidades locales para elaborar sus propios planes de gestión de residuos urbanos, eso sí, de acuerdo con lo que establezca en los planes de la respectiva Comunidad Autónoma.

\section{ALGUNAS CONCLUSIONES}

5.1. La Ley $11 / 1997$, de 24 de abril, introduce en el servicio local de gestión de residuos, sin alterar su naturaleza de servicio público, una variante fundamental, en la medida que la recogida y el tratamiento de los residuos de envases se encomienda a los agentes económicos, bajo su plena responsabili-

45 El Programa de Gestión de Residuos Municipales de Cataluña, DOGC 6 de agosto de 1996, aprobado en desarrollo del Programa General del art. 6 de la Ley 6/1993, no tiene precisamente este carácter de instrumento de planificación sectorial vinculante para los entes locales. Al contrario, su relación con el Fondo de Gestión de Residuos (art. 51 L. 6/93) lo sitúa en el marco de la cooperación económica voluntaria, establecido por el Plan Director de Inversiones Locales de Cataluña y del Plan Único de Obras y Servicios integrado en el anterior (arts. 169 a 172 L. 8/87, Municipal de Cataluña). 
dad. Esta encomienda o misión de servicio público se hace, en principio, en términos absolutos, mediante la imposición del sistema de depósito, devolución y retorno como el general y obligatorio para envasadores, comerciantes y otros agentes implicados. Este sistema comporta, además, una interiorización del coste social que generan estos residuos en los costes de producción y de comercialización, mediante un instrumento económico puramente de mercado. La cantidad que el consumidor ha de dejar en depósito y su posterior devolución atribuye al residuo de envase o al envase usado ya no un valor, sino un precio individual que los inserta en el mercado, y hace que la cadena que va desde la producción hasta la venta al detall sea reversible o que, si se rompe, el valor del residuo no se pierda, con lo que el principio de «quien contamina paga» se hace plenamente efectivo. El sistema de depósito excluye pues la alternativa de la fiscalidad sobre los envases, como forma de interiorización del coste social.

5.2. El carácter absoluto del sistema de depósito se relativiza, sin embargo, con la alternativa que se ofrece a los agentes económicos para que, en su lugar, establezcan un sistema de recogida en el domicilio de los usuarios o en la vía pública. La interiorización se consigue entonces por un sistema de contribución de cada agente económico a la empresa común que se hace cargo de la recogida selectiva y del tratamiento. El instrumento económico pasa a ser una suerte de «fiscalidad privada» establecida entre los agentes económicos implicados. Pero la gran diferencia con el sistema de depósito está en que el incentivo para el consumidor ya no es económico, sino que se remite a su grado de conciencia cívica y ambiental y, en definitiva, al esfuerzo, que los poderes públicos y el sistema integrado han de hacer para que esta conciencia aumente o, más crudamente, empiece a existir. Los resultados esperables de los sistemas integrados serán pues mucho más reducidos que los del sistema de depósito. Además, el principio de «quien contamina paga» ya no es plenamente efectivo, puesto que escapan al mismo los residuos de envases que no son recogidos selectivamente; se mantiene así un coste social del que han de seguir haciéndose cargo los municipios y demás entidades locales y, en definitiva, los vecinos.

5.3. Pero la excepción de los sistemas integrados tiene a su vez otra, que permite a los agentes económicos trasladar la gestión de la recogida selectiva de nuevo a las entidades locales, haciéndose cargo el sistema integrado de sus costes. Aparentemente, volvemos a una vía tributaria; pero a diferencia de una fiscalidad unilateral clásica, se trata ahora de una «fiscalidad pactada o contractual» entre los sistemas integrados y las entidades locales. Por la vía de las sucesivas excepciones del sistema general de depósito se vuelve, en la práctica, al punto de partida, con la diferencia de que la contraprestación que los entes locales han de percibir por la prestación del servicio ya o la pueden establecer unilateralmente, como cualquier tasa o precio público, sino que se ven obliga- 
LOS ENVASES Y EL SERVICIO MUNICIPAL DE RECOGIDA ...

dos a pactarla con los agentes económicos y, además, no directamente sino con la intermediación de la Administración autonómica.

5.4. Esta intervención de las Comunidades Autónomas que, más allá del ejercicio de las potestades que les serían propias de ordenación, planificación y coordinación, asumen la facultad de convenir condiciones con los sistemas integrados y la potestad de recaudación y redistribución de las aportaciones privadas a las entidades locales, agota los límites de la autonomía local —si no los traspasa - que es una de las condiciones que la ley impone a la potestad de coordinación de los entes locales por parte de las Administraciones autonómicas.

5.5. El concepto de coste diferencial debería tender a identificarse con el coste efectivo de inversión y explotación de la recogida selectiva, puesto que las entidades locales ya se hacen cargo — sin compensación alguna del sistema integrado- de la recogida y del tratamiento de los residuos de envases que los usuarios no entregan o no depositan selectivamente. A su vez, hay el coste diferencial de los costes adicionales, que son factores distintos y que deben añadirse al coste de las inversiones en recogida y de la explotación del servicio.

5.6. Es imprescindible que se cumplan las previsiones del art. $18 \mathrm{del} \mathrm{Re}$ glamento, sobre el control autonómico de la autogestión de los envases industriales y comerciales por sus poseedores finales. 
